\title{
Seasonal Responses of Terrestrial Carbon Cycle to Climate Variations in CMIP5 Models: Evaluation and Projection ${ }^{\mathscr{O}}$
}

\author{
YONGWEN LIU \\ Sino-French Institute for Earth System Science, College of Urban and Environmental Sciences, Peking University, Beijing, China

\section{SHILONG PIAO} \\ Sino-French Institute for Earth System Science, College of Urban and Environmental Sciences, Peking University, and Key \\ Laboratory of Alpine Ecology and Biodiversity, Institute of Tibetan Plateau Research, and Chinese Academy of Sciences \\ Center for Excellence in Tibetan Plateau Earth Sciences, Chinese Academy of Sciences, Beijing, China
}

\author{
XU LIAN
}

Sino-French Institute for Earth System Science, College of Urban and Environmental Sciences, Peking University, Beijing, China

\section{PHILIPPE CIAIS}

Laboratoire des Sciences du Climat et de l'Environnement, CEA CNRS UVSQ, Gif Sur Yvette, France

\section{W. KOLBY SMITH}

School of Natural Resources and the Environment, The University of Arizona, Tucson, Arizona

(Manuscript received 27 July 2016, in final form 18 March 2017)

\begin{abstract}
Seventeen Earth system models (ESMs) from phase 5 of the Coupled Model Intercomparison Project (CMIP5) were evaluated, focusing on the seasonal sensitivities of net biome production (NBP), net primary production (NPP), and heterotrophic respiration ( $\mathrm{Rh}$ ) to interannual variations in temperature and precipitation during 1982-2005 and their changes over the twenty-first century. Temperature sensitivity of NPP in ESMs was generally consistent across northern high-latitude biomes but significantly more negative for tropical and subtropical biomes relative to satellite-derived estimates. The temperature sensitivity of NBP in both inversion-based and ESM estimates was generally consistent in March-May (MAM) and SeptemberNovember (SON) for tropical forests, semiarid ecosystems, and boreal forests. By contrast, for inversion-based NBP estimates, temperature sensitivity of NBP was nonsignificant for June-August (JJA) for all biomes except boreal forest; whereas, for ESM NBP estimates, the temperature sensitivity for JJA was significantly negative for all biomes except shrublands and subarctic ecosystems. Both satellite-derived NPP and inversion-based NBP are often decoupled from precipitation, whereas ESM NPP and NBP estimates are generally positively correlated with precipitation, suggesting that ESMs are oversensitive to precipitation. Over the twenty-first century, changes in temperature sensitivities of NPP, Rh, and NBP are consistent across all RCPs but stronger under more intensive scenarios. The temperature sensitivity of NBP was found to decrease in tropics and subtropics and increase in northern high latitudes in MAM due to an increased temperature sensitivity of NPP. Across all biomes, projected temperature sensitivity of NPP decreased in JJA and SON. Projected precipitation sensitivity of NBP did not change across biomes, except over grasslands in MAM.
\end{abstract}

Supplemental information related to this paper is available at the Journals Online website: http://dx.doi.org/10.1175/ JCLI-D-16-0555.s1.

Corresponding author: Shilong Piao, slpiao@pku.edu.cn

\section{Introduction}

Atmospheric $\mathrm{CO}_{2}$ seasonal cycle is controlled by the seasonal responses of terrestrial carbon cycle to climate (Forkel et al. 2016; Graven et al. 2013; Keeling et al. 1996; Randerson et al. 1997). Interannual anomalies of 
climate superimposed on the seasonal cycle modulate the response of terrestrial $\mathrm{CO}_{2}$ fluxes to climate season specifically. For instance, a large body of evidence shows that warmer springs are associated with an enhanced $\mathrm{CO}_{2}$ uptake (Keenan et al. 2014; Wolf et al. 2016), implying that the interannual sensitivity of the net $\mathrm{CO}_{2}$ flux [net biome production (NBP)] is positively related to spring temperature variations. In summer, since warmer years are often dryer across the temperate zone, the interannual sensitivity of NBP to temperature variations generally is negative (Angert et al. 2005). In autumn, years with warmer climate were analyzed by Piao et al. (2008) to be associated with an abnormal release of $\mathrm{CO}_{2}$ (i.e., suggesting a negative interannual sensitivity of NBP to autumn temperature), but other studies found the opposite, namely that warmer autumns extend the growing season, which results in increased $\mathrm{CO}_{2}$ uptake (Dragoni et al. 2011).

Accurate understanding of the seasonal impact of climate change on terrestrial carbon fluxes is essential for evaluating and projecting atmospheric $\mathrm{CO}_{2}$ seasonality (Forkel et al. 2016; Zhao and Zeng 2014). Earth system models (ESMs) are widely used to assess terrestrial carbon cycle responses to climate change across multiple temporal scales, but the large spread in the simulation results across ESMs has limited our ability to make inferences (Todd-Brown et al. 2014; Todd-Brown et al. 2013; Ahlström et al. 2012). In recent years, some observation-based products of carbon flux have been reported and are valuable data to test terrestrial carbon cycle process in ESMs, including satellite-derived net primary production (NPP) Smith et al. (2016) and inversion-based NBP (Chevallier et al. 2014; Chevallier et al. 2005; Chevallier et al. 2010). Using these products enables the evaluation of the performance of ESMs in modeling the seasonal responses of the terrestrial carbon cycle to climate variations.

Over the twenty-first century, global mean surface temperatures are projected to continue to rise under all representative concentration pathways (RCPs) from ESMs participating in phase 5 of the Coupled Model Intercomparison Project (CMIP5) (Collins et al. 2013). Future warming has seasonal asymmetry, with a larger warming in winter than in summer, resulting in the reduction of the seasonal cycle of temperature (Dwyer et al. 2012). Furthermore, projected changes in precipitation are also not uniform across seasons. For instance, increases in precipitation are larger in late winter-early spring (February-April) in the northeastern United States over the twenty-first century under RCP8.5 from CMIP5 ESMs (Lynch et al. 2016). These complex seasonal patterns of climate change are a main reason that season-specific responses of the terrestrial carbon cycle to climate change over the twenty-first century remain largely unknown.

In this study, we investigate the seasonal sensitivities of terrestrial carbon fluxes to interannual climate variations in CMIP5 ESMs, and how these sensitivities change during the twenty-first century. Specifically, we aim to 1) evaluate CMIP5 ESMs for their seasonal dynamics of NPP and NBP sensitivities to interannual climate variations, 2) examine changes in seasonal sensitivities of terrestrial NBP to interannual climate variations during the twenty-first century, and 3) identify which carbon flux component, NPP or heterotrophic respiration $(\mathrm{Rh})$, leads to the twenty-first century changes in seasonal sensitivities of the net $\mathrm{CO}_{2}$ balance (NBP) to interannual climate variations in ESMs.

\section{Material and methods}

\section{a. Terrestrial carbon fluxes and climate variables in Earth system models}

We used historical ("historical" experiment; 18502005) and future representative concentration pathway 2.6, 4.5, 6.0, and 8.5 simulations (RCP2.6, RCP4.5, RCP6.0, and RCP8.5, respectively; 2006-2100) of the CMIP5 ESMs (Taylor et al. 2012). Both historical carbon fluxes (NPP, Rh, and NBP) and climate variables (air temperature, precipitation, and surface downwelling shortwave radiation variables) from 17 ESMs were used, including BNU-ESM, CanESM2, CCSM4, CESM1(BGC), HadGEM2-CC, HadGEM2-ES, IPSL-CM5A-LR, IPSLCM5B-LR, MIROC-ESM, MIROC-ESM-CHEM, MPIESM-LR, MPI-ESM-MR, MRI-ESM1, NorESM1-M, and NorESM1-ME. (Expansions of acronyms are available online at http://www.ametsoc.org/PubsAcronymList.) The number of ESMs having so-called historical and RCP2.6, RCP4.5, RCP6.0, and RCP8.5 runs is 17, 12, 16, 9, and 16, respectively (see Table S1 in the supplemental material).

We downloaded monthly output of ESMs from the Program for Climate Model Diagnosis and Intercomparison (PCMDI) server: Earth System Grid Federation (Cinquini et al. 2014) (http://cmip-pcmdi.llnl.gov/cmip5). For each individual model, only output from the first realization (r1i1p1) was used in this study. The output was regridded to $1^{\circ} \times 1^{\circ}$ using the first-order conservative remapping scheme (Jones 1999) in Climate Data Operators (https://code.zmaw.de/projects/cdo) following several previous studies (e.g., Y. Liu et al. 2016; Wang et al. 2016; Zappa et al. 2015; Curry et al. 2014; Donat et al. 2014; Torres and Marengo 2014; Sillmann et al. 2013). The study region was limited to the land area with active vegetation, defined as grid cells where the 
annual mean normalized difference vegetation index (NDVI) during 1982-2009 was larger than 0.1. The NDVI data were the third-generation GIMMS NDVI data from AVHRR sensors (NDVI3g), obtained from the Global Inventory Monitoring and Modeling Studies (GIMMS) group (Pinzon and Tucker 2014). Please note that the active vegetation defined by historical NDVI may not be exactly the same as that in ESMs, and modeling vegetated land area may change with time.

\section{b. Satellite-derived NPP, inversion-based NBP, and climate datasets}

Global monthly satellite-derived NPP data from 1982-2011 with $1^{\circ} \times 1^{\circ}$ spatial resolution were obtained from Smith et al. (2016). This NPP dataset was estimated using the Moderate Resolution Imaging Spectroradiometer (MODIS) NPP algorithm driven by the third-generation GIMMS fraction of photosynthetically active radiation (FPAR) absorbed by the vegetation (FPAR3g) and leaf area index (LAI3g) (Zhu et al. 2013), following Eq. (1) in Smith et al. (2016).

Global monthly NBP from 1979 to 2015 with $1.875^{\circ}$ latitude $\times 3.75^{\circ}$ longitude spatial resolution was obtained from version 15.2 of the Monitoring Atmospheric Composition and Climate-Interim Implementation (MACC-II) $\mathrm{CO}_{2}$ inversion product from the Laboratoire des Sciences du Climat et de l'Environnement (LSCE) (Chevallier et al. 2014, 2005, 2010). The surface-atmosphere net land carbon fluxes were estimated by atmospheric $\mathrm{CO}_{2}$ inversions using atmospheric $\mathrm{CO}_{2}$ concentration measurements across the globe and an atmospheric transport model. NBP is retrieved from the inversion after subtracting the influence of fossil fuel $\mathrm{CO}_{2}$ emissions (assumed to be perfectly known) from atmospheric $\mathrm{CO}_{2}$ gradients.

Monthly air temperature, precipitation, and cloud cover from 1901 to 2013 with spatial resolution of $0.5^{\circ} \times 0.5^{\circ}$ were downloaded from the University of East Anglia Climatic Research Unit [CRU Time Series, version 3.22 (CRU TS3.22); http://catalogue.ceda. ac.uk/uuid/3f8944800cc48e1cbc29a5ee12d8542d] (Jones and Harris 2008). Both inversion-based NBP and CRU climate data were regridded to $1^{\circ} \times 1^{\circ}$ before the other analysis.

\section{c. Biome classifications}

Biome classifications in this study were defined according to the standard MODIS land cover type data product (MCD12Q1; http://glcf.umd.edu/data/lc/) in the IGBP land cover type classification (Friedl et al. 2010) and the Köppen-Geiger climate classification (http://koeppen-geiger.vu-wien.ac.at/present.htm) (Kottek et al. 2006). Six biomes were considered: tropical forests, temperate forests, boreal forests, semiarid ecosystems, grasslands, and shrublands and subarctic ecosystems (Fig. S1 in the supplemental material). Forests in the MCD12Q1 were split into tropical forests, temperate forests, and boreal forests using the Köppen-Geiger classification. Semiarid ecosystems include arid areas in the Köppen-Geiger climate classification, and all savanna and shrublands at latitudes south of $50^{\circ} \mathrm{N}$. Grasslands correspond to MCD12Q1 land cover definition at latitudes south of $60^{\circ} \mathrm{N}$. Shrublands and subarctic ecosystems include MCD12Q1 land cover classes of savanna and shrublands at latitudes north of $50^{\circ} \mathrm{N}$, and grasslands at latitudes north of $60^{\circ} \mathrm{N}$.

\section{d. Analysis}

The monthly interannual sensitivities of satellitederived NPP and inversion-based NBP to climate variations were calculated using CRU TS3.22 climate during the period 1982-2005. Monthly interannual sensitivities of NPP, Rh, and NBP in CMIP5 ESMs were obtained using ESM climate during 1982-2005 (historical simulation) and 2076-99 (each RCP). The yearly series of ESM fluxes each month were detrended. Then interannual sensitivities each month were calculated using a multiple regression approach:

$$
y=\gamma^{T} T+\gamma^{P} P+\gamma^{R} R+b+\varepsilon,
$$

where $y$ is the detrended anomaly of carbon flux (NPP, $\mathrm{Rh}$, or NBP), $T$ is the detrended anomaly of air temperature, $P$ is the detrended anomaly of precipitation, $b$ is a constant, and $\varepsilon$ is the residual error term. When calculating the sensitivities in ESMs, $R$ is the detrended anomaly of shortwave downwelling radiation but is the detrended anomaly of cloud cover when calculating the sensitivities of satellite-derived NPP and inversionbased NBP because radiation was not available in CRU TS3.22. Therefore, interannual radiation sensitivities of carbon fluxes were only analyzed for ESMs. The apparent interannual sensitivities of carbon fluxes to interannual variations of temperature, precipitation, and shortwave downwelling radiation are $\gamma^{T}, \gamma^{P}$, and $\gamma^{R}$ (Piao et al. 2013), respectively, where "apparent sensitivity" indicates the partial derivative of carbon flux to a given climate factor with other climate factors varying as in the real world. These gamma notations therefore differ from the gamma notation in previous studies focusing on the Coupled Climate-Carbon Cycle Model Intercomparison Project (C4MIP) (Friedlingstein et al. 2006). In Friedlingstein et al. (2006), gamma is used to define a carbon flux sensitivity to climate change including all aspects of meteorology (e.g., temperature, 
precipitation, and shortwave downwelling radiation), and therefore is not able to be compared with $\gamma^{T}, \gamma^{P}$, and $\gamma^{R}$ in this study.

We separated the direct effect of $T$ and $P$ on NPP compared with their effect via soil moisture for each biome in ESMs using a multiple regression approach:

$$
y=\gamma^{T_{-}{ }^{M}} T+\gamma^{P_{-} M} P+\gamma^{R_{-}{ }^{M}} R+\gamma^{M} S+b+\varepsilon,
$$

where $y$ is the detrended anomaly of carbon flux (NPP); $S$ is the detrended anomaly of surface soil moisture (mrsos); $T, P, R, b$, and $\varepsilon$ are as in Eq. (1); $\gamma^{T-M}, \gamma^{P-M}$, and $\gamma^{R-M}$ are the fitted direct effect of $T, P$, and $R$ on NPP; and $\gamma^{M}$ is the apparent interannual sensitivity of NPP to surface soil moisture.

The spatial patterns of monthly sensitivities of carbon fluxes to interannual climate variations $(T, P$, and $R$ ) were calculated by Eq. (1) using carbon fluxes and climate variables in each $1^{\circ} \times 1^{\circ}$ grid. The sensitivities in each $1^{\circ}$ latitude band were averaged to obtain the zonal distribution of sensitivities in each month except for inversion-based NBP responses to $T$ and $P$. When analysis spatial patterns of NBP sensitivity based on inversion-based NBP, we aggregated each variable over the following latitudinal bands: $50^{\circ}-90^{\circ} \mathrm{N}, 23^{\circ}-$ $50^{\circ} \mathrm{N}, 23^{\circ} \mathrm{S}-0^{\circ}, 0^{\circ}-23^{\circ} \mathrm{N}$, and $23^{\circ}-50^{\circ} \mathrm{S}$. To perform analysis of the seasonal sensitivities of carbon fluxes at biome scale, each variable (NPP, Rh, NBP, temperature, precipitation, and shortwave downwelling radiation) was aggregated in each biome. Then, the variables were summed over the following periods in each year: March-May (MAM), June-August (JJA), September-November (SON), and DecemberFebruary (DJF). The aggregated variables in each season were detrended separately and then used to calculate the biome-averaged interannual climate sensitivities of seasonal carbon fluxes based on Eq. (1). Future changes (indicated with $\Delta$ ) in $\gamma^{T}, \gamma^{P}$, and $\gamma^{R}$ were calculated as the differences between 2069-98 and 19752004 assuming no change in biome area. We examined the significance of these changes using a Wilcoxon signed-rank test following Collins et al. (2013) and Y. Liu et al. (2016).

In the following text, the value of $\gamma$ is represented as $X \pm \mathrm{SE}$, where $X$ is the value of the interannual sensitivity of carbon fluxes $\gamma$, and SE is the standard error of $\gamma$ (regression fit uncertainty). The multimodel distribution of $\gamma$ is represented as $X_{\mathrm{p} 25}^{\mathrm{p} 75} \pm U$, where $X$ is the median of apparent sensitivities of carbon fluxes across models $\gamma$, $\mathrm{p} 75$ is the 0.75 quantile, $\mathrm{p} 25$ is the 0.25 quantile, and $U$ is the multimodel mean SE (average of the regression fit uncertainty).

\section{Results and discussion}

\section{a. Interannual temperature sensitivities of seasonal carbon fluxes}

\section{1) TROPICAL FORESTS}

In tropical forests, $\gamma_{\mathrm{NBP}}^{T}$ is negative in MAM, JJA, SON, and DJF during 1982-2005 in most ESMs (Fig. S2 in the supplemental material), resulting in negative multimodel median $\gamma_{\mathrm{NBP}}^{T}$ ranging from $-118.2_{-154.0}^{-77.4} \pm$ $23.4 \mathrm{TgCmonth}{ }^{-1} \mathrm{~K}^{-1}(p<0.001)$ in MAM to $-88.0_{-161.8}^{-66.0} \pm 30.1 \mathrm{TgC}$ month $^{-1} \mathrm{~K}^{-1}(p<0.001)$ in DJF (the wet season in the southern tropics; Fig. 1a). This negative NBP- $T$ relationship is consistently diagnosed across most ESMs (Fig. S2), and is mainly due to negative $\gamma_{\mathrm{NPP}}^{T}$, rather than positive $\gamma_{\mathrm{Rh}}^{T}$ (Figs. 1-5). NPP is negatively related with $T$, with a multimodel median $\gamma_{\mathrm{NPP}}^{T}$ ranging from $-107.0_{-143.0}^{-59.6} \pm 26.9 \mathrm{TgC} \mathrm{month}^{-1} \mathrm{~K}^{-1}(p<$ $0.001)$ in SON to $-82.3_{-125.6}^{-41.0} \pm 26.2 \mathrm{TgCmonth}^{-1} \mathrm{~K}^{-1}$ $(p<0.001)$ in JJA (Fig. 1a). The ESMs' $\gamma_{\mathrm{Rh}}^{T}$ in MAM and JJA is $14.3_{3.5}^{27.3} \pm 14.8(p<0.001)$ and $11.2_{0.4}^{23.5} \pm$ 14.7 $\mathrm{TgC}$ month ${ }^{-1} \mathrm{~K}^{-1}(p<0.001)$, respectively, but is nonsignificant in SON and DJF (Fig. 1a).

The satellite-derived $\gamma_{\mathrm{NPP}}^{T}$ is marginally significantly negative in SON $\left(-109.3 \pm 61.4 \mathrm{TgCmonth}^{-1} \mathrm{~K}^{-1}\right.$, $p=0.09$ ) during 1982-2005, which is comparable with the multimodel median $\gamma_{\mathrm{NPP}}^{T}$. But in MAM, JJA, and DJF, satellite-derived $\gamma_{\mathrm{NPP}}^{T}$ is nonsignificant, unlike negative $\gamma_{\mathrm{NPP}}^{T}$ in the ESMs (Fig. 1a). Tropical vegetation is thought to be close to the high temperature threshold for NPP (Corlett 2011; Doughty and Goulden 2008). Most areas $(88 \%)$ of current tropical forests experience mean annual temperatures greater than $20^{\circ} \mathrm{C}$ (Wood et al. 2012), while leaf temperatures in tropical forests are often higher than $35^{\circ} \mathrm{C}$ (Doughty and Goulden 2008), which is near the thermal optimum for plants under current atmospheric $\mathrm{CO}_{2}$ concentrations less than $380 \mathrm{ppm}$ (Wood et al. 2012). NPP should thus become decoupled from $T$ when temperature is optimum, and negatively related to $T$ under above-optimal temperature. It seems that CMIP5 ESMs overestimated the negative effect of $T$ on the NPP in MAM, JJA, and DJF with more negative $\gamma_{\mathrm{NPP}}^{T}$ compared to satellite-derived $\gamma_{\mathrm{NPP}}^{T}$. Here, modeled $\gamma_{\mathrm{NPP}}^{T}$ is calculated by the multiple regression approach in Eq. (1) using the variables outputted by individual ESMs, and therefore may not be exactly consistent with model-specific physiological processes (Rogers et al. 2017). We note that there are also uncertainties in satellite-derived NPP in tropical forests. The calculation of satellite-derived NPP is influenced by FPAR and LAI, both of which, however, can saturate in the tropical forests Smith et al. (2016). Moreover, usable optical satellite images are limited in tropical forests because of persistent cloud 
(a) Tropical forests

(b) Temperate forests

(c) Boreal forests

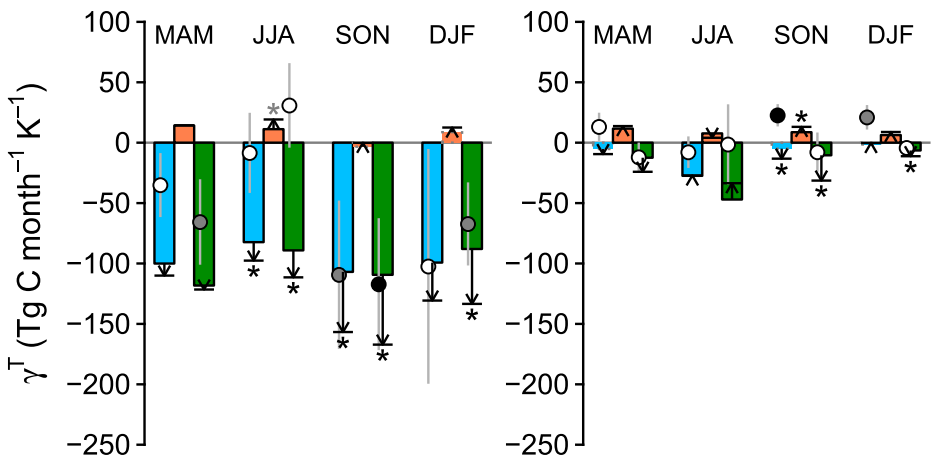

(d) Semi-arid ecosystems

(e) Grasslands
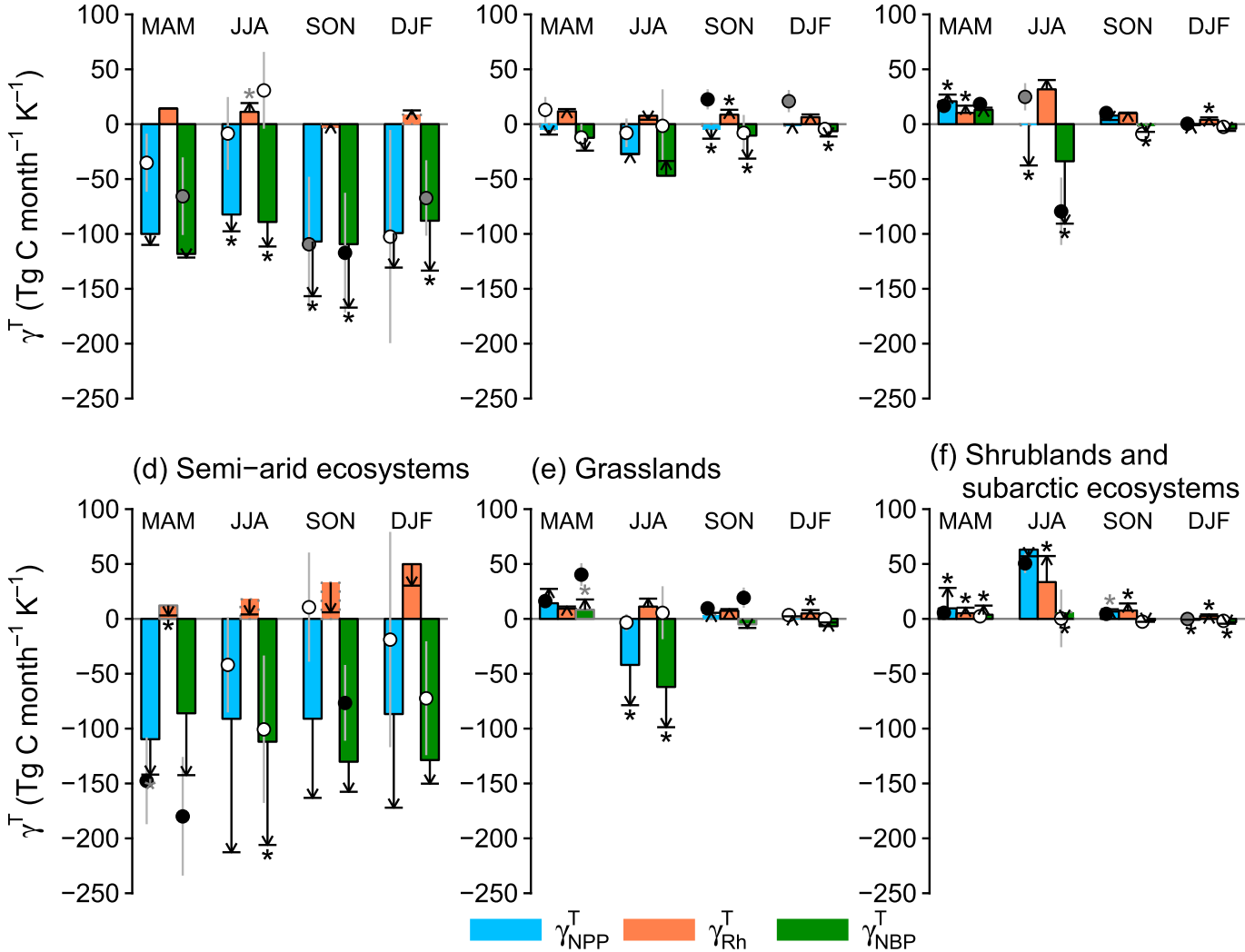

(f) Shrublands and subarctic ecosystems

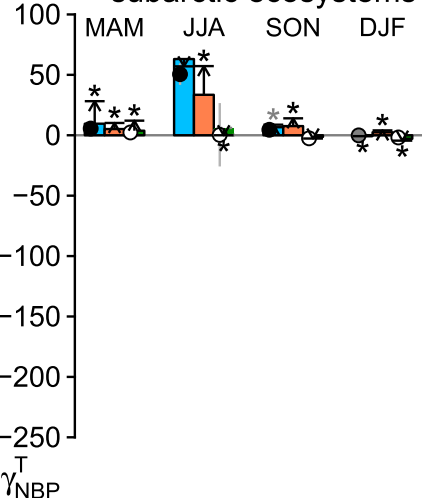

FIG. 1. Multimodel median seasonal $\gamma_{\mathrm{NPP}}^{T}, \gamma_{\mathrm{Rh}}^{T}$, and $\gamma_{\mathrm{NBP}}^{T}$ across vegetation types in the period 1982-2005 and their changes from 1982 to 2099 under RCP4.5. The dots represent observation derived $\gamma^{T}$ in the period 1982-2005. The black, gray, and white dots indicate that $\gamma^{T}$ is significant (at the 5\% level), marginally significant (at the $10 \%$ level), and nonsignificant, respectively. The gray vertical lines across the dots indicate the standard error of observation derived $\gamma^{T}$. The bars mean the $\gamma^{T}$ in the period 1982-2005. The bars with black solid, gray solid, and gray dashed borders mean that the multimodel median $\gamma^{T}$ is significant (at the $5 \%$ level), marginally significant (at the $10 \%$ level), and nonsignificant using a Wilcoxon signed-rank test, respectively. The arrows mean the changes in multimodel median seasonal $\gamma^{T}$ from 1982 to $2099\left(\Delta \gamma^{T}\right)$ under RCP4.5. The black and gray stars mean that multimodel median $\Delta \gamma^{T}$ is significant (at the $5 \%$ level) and marginally significant (at the $10 \%$ level) using a Wilcoxon signed-rank test, respectively.

cover, particular in the rainy season (e.g., JJA), posing a challenge to the interannual analysis (Reiche et al. 2016). Finally, satellite-derived $\gamma_{\mathrm{NPP}}^{T}$ could be impacted by other constraints in the light use efficiency model, including a partially temperature-driven vapor pressure deficit (VPD) constraint and a partially temperature-driven autotrophic respiration $(\mathrm{Ra})$ equation.

Over tropical forests, the inversion-based $\gamma_{\mathrm{NBP}}^{T}$ during 1982-2005 in MAM, SON, and DJF is $-65.6 \pm 35.4$ $(p=0.078),-117.1 \pm 54.6(p=0.044)$, and $-67.2 \pm$ $34.4 \mathrm{TgC} \mathrm{month}{ }^{-1} \mathrm{~K}^{-1}(p=0.065)$, respectively, which are comparable with ESM simulations (Fig. 1a). However, in JJA, inversion-based $\gamma_{\mathrm{NBP}}^{T}$ is nonsignificant. It is noteworthy that the surface $\mathrm{CO}_{2}$ mixing ratio measurement sites used in the estimation of inversion-based NBP, are mainly distributed in the middle and high latitudes, and over tropical oceans, but scarce on tropical lands (Chevallier et al. 2010).
This causes uncertainties of inversion-based $\gamma_{\mathrm{NBP}}^{T}$ in tropical forests, although the inversion-based NBP in tropical forest is partly constrained by the $\mathrm{CO}_{2}$ mixing ratios measured in other regions (Chevallier et al. 2010). To better evaluate the tropical $\gamma_{\mathrm{NBP}}^{T}$ from ESMs more accurate estimation of responses of seasonal NBP to $T$ in tropical forests are needed. For example, manipulative warming experiments could be utilized to improve our understanding of tropical forests carbon balance responses to climate change (Cavaleri et al. 2015; Norby et al. 2016).

By the end of the twenty-first century, $\gamma_{\mathrm{NBP}}^{T}$ of tropical forests becomes more negative in most ESMs under RCP4.5, with a multimodel $\Delta \gamma_{\mathrm{NBP}}^{T}$ ranging from $-47.8_{-902}^{-10.1} \pm 10.2 \mathrm{TgCmonth}^{-1} \mathrm{~K}^{-1}(p=0.013)$ in SON to $-19.0_{-37.4}^{3.0} \pm 0.1 \mathrm{TgCmonth}^{-1} \mathrm{~K}^{-1}(p=0.049)$ in DJF (Fig. 1a). Such decreases in $\gamma_{\mathrm{NBP}}^{T}$ are mainly contributed by the significant decreases in $\gamma_{\mathrm{NPP}}^{T}$ with $\Delta \gamma_{\mathrm{NPP}}^{T}$ ranging 
(a) Observation

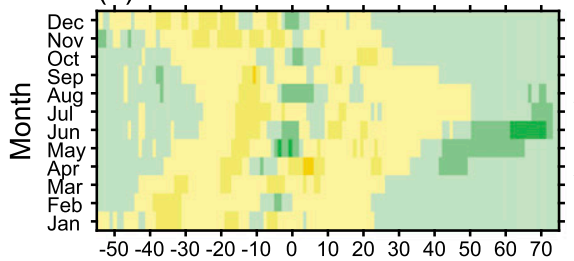

(d) CCSM4

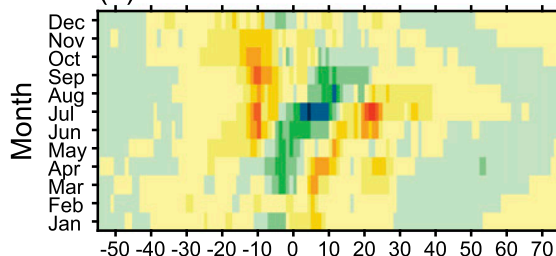

(g) GFDL-ESM2M

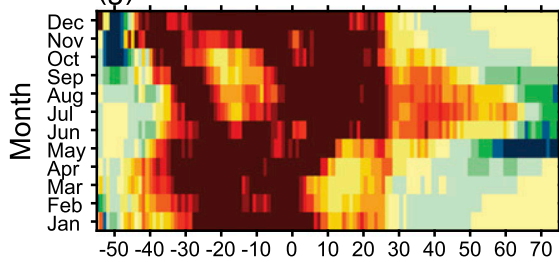

(j) IPSL-CM5A-LR

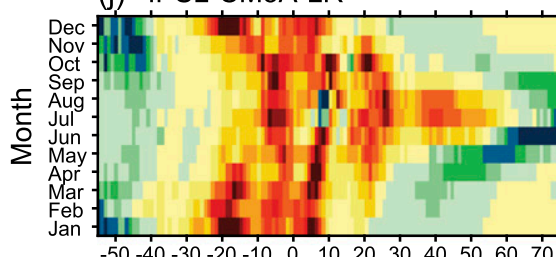

(m)MIROC-ESM-CHEM

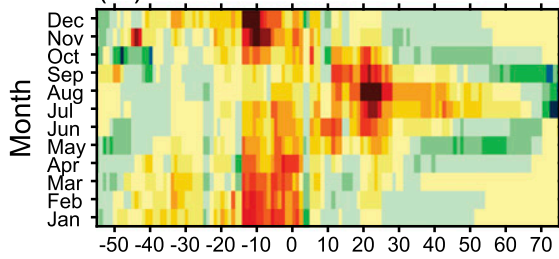

(p) MRI-ESM1

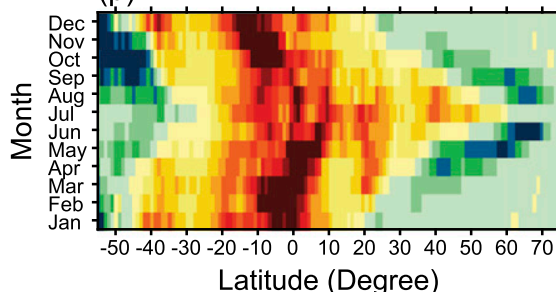

(b) BNU-ESM

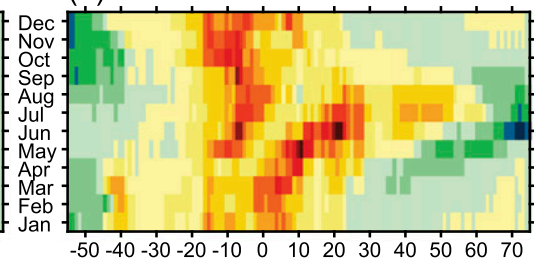

(e) CESM1-BGC

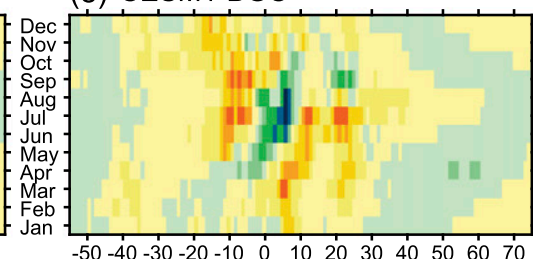

(h) HadGEM2-CC

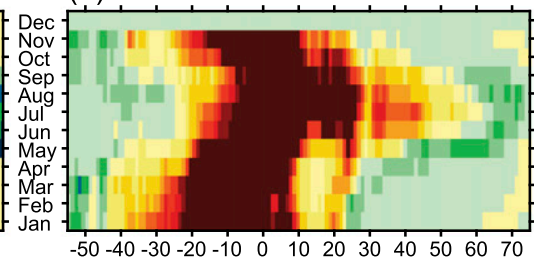

(k) IPSL-CM5B-LR

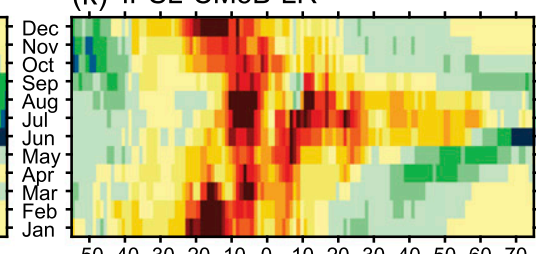

(n) MPI-ESM-LR

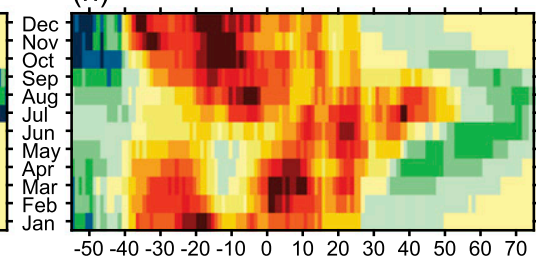

(q) NorESM1-M

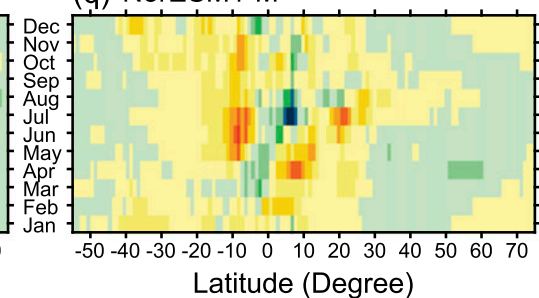

(c) CanESM2

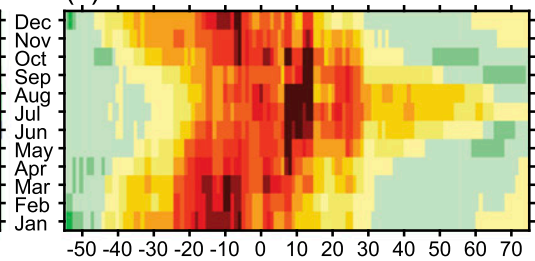

(f) GFDL-ESM2G

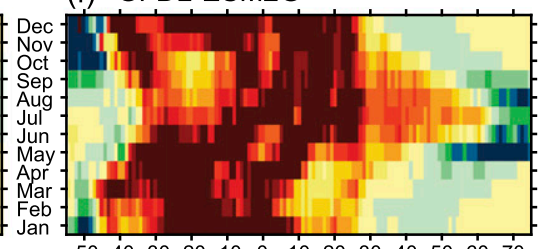

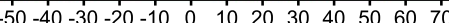

(i) HadGEM2-ES

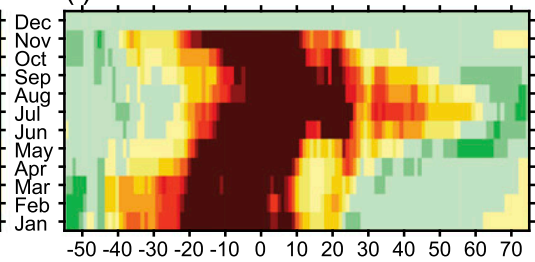

(I) MIROC-ESM

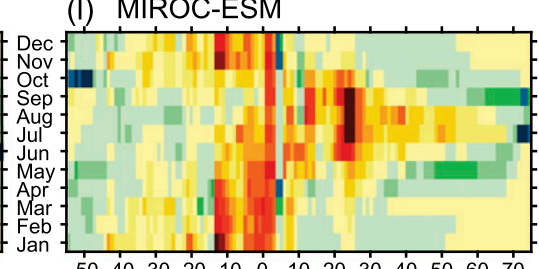

(o) MPI-ESM-MR

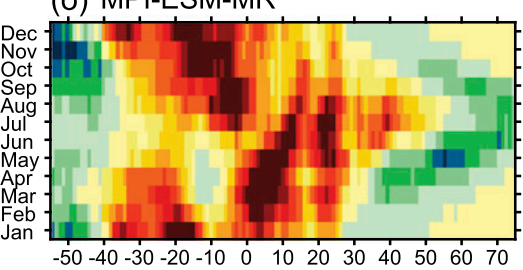

(r) NorESM1-ME

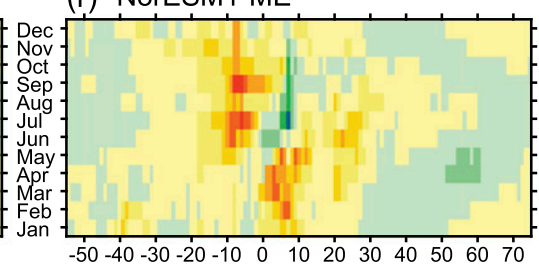

Latitude (Degree)

$$
\begin{aligned}
& \begin{array}{llll}
-16 & -14 & -12 & -1
\end{array} \\
& \gamma_{\text {NPP }}^{\top} \text { in the period 1982-2005 }\left(\mathrm{g} \mathrm{C} \mathrm{m}^{-2} \text { month }^{-1} \mathrm{~K}^{-1}\right)
\end{aligned}
$$

FIG. 2. Spatial distributions of observed and simulated monthly $\gamma_{\mathrm{NPP}}^{T}$ in the period $1982-2005 ; \gamma_{\mathrm{NPP}}^{T}$ is estimated using Eq. (1). 
(a) BNU-ESM

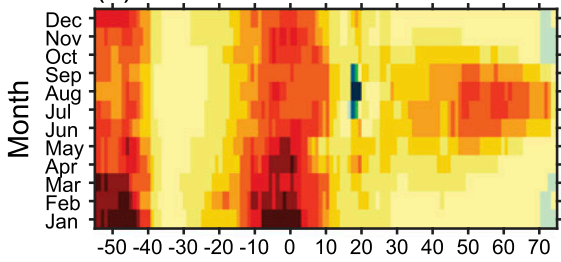

(d) CESM1-BGC

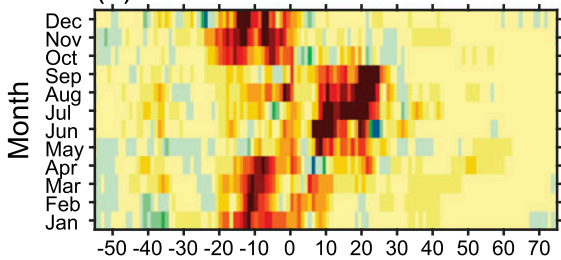

(g) HadGEM2-CC

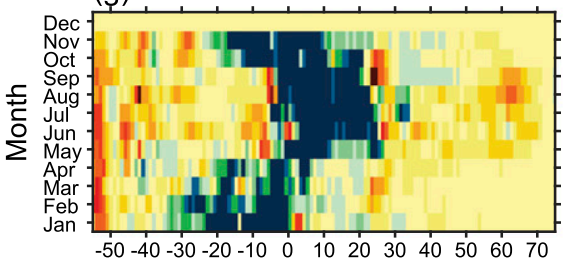

(j) IPSL-CM5B-LR

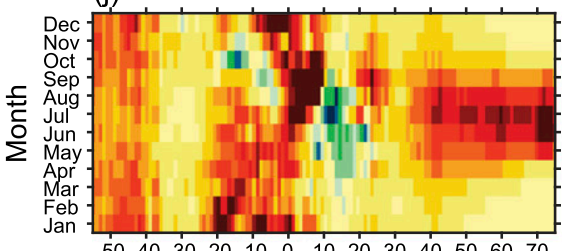

(m) MPI-ESM-LR

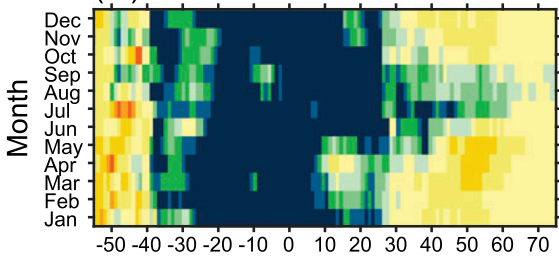

(p) NorESM1-M

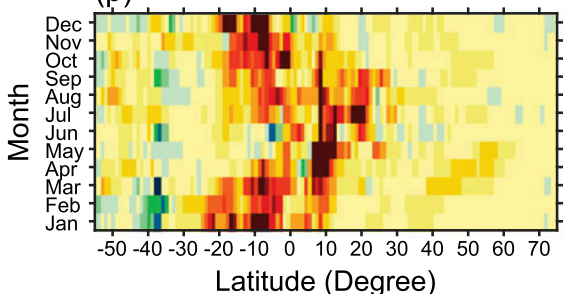

(b) CanESM2

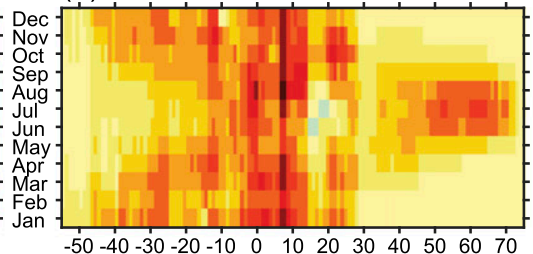

(e) GFDL-ESM2G

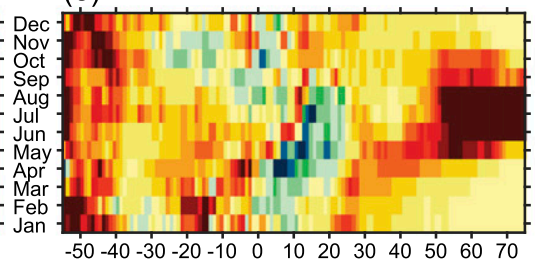

(h) HadGEM2-ES

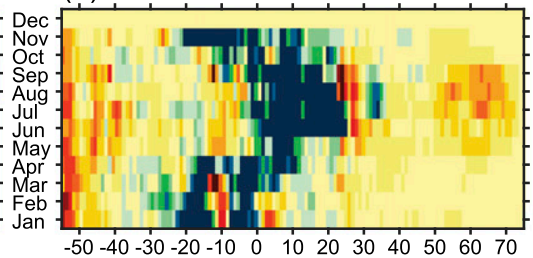

(k) MIROC-ESM

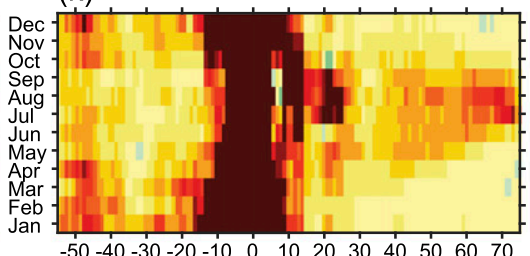

(n) MPI-ESM-MR

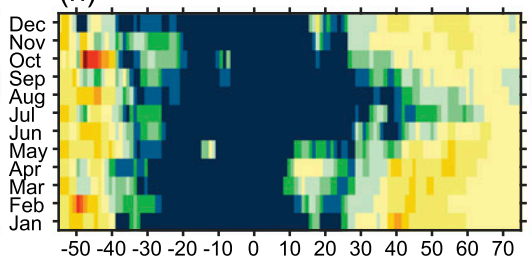

(q) NorESM1-ME

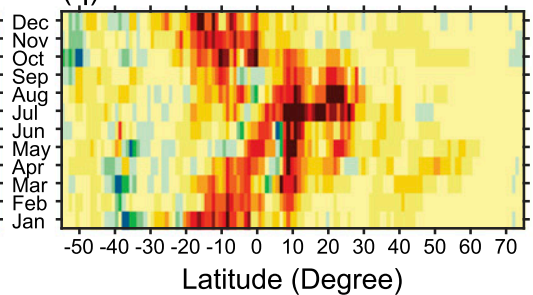

(c) $\operatorname{ccs} 4$

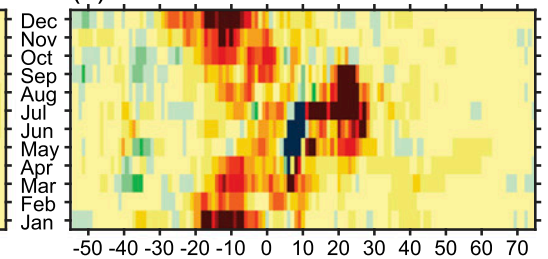

(f) GFDL-ESM2M

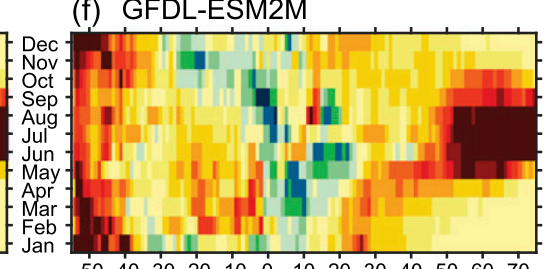

(i) IPSL-CM5A-LR

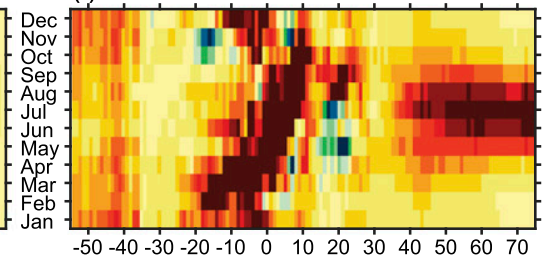

(I) MIROC-ESM-CHEM

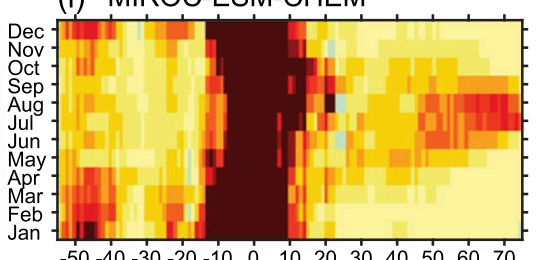

$-50-40-30-20-10 \quad 0 \quad 1020 \quad 3040 \quad 50 \quad 6070$

(o) MRI-ESM1

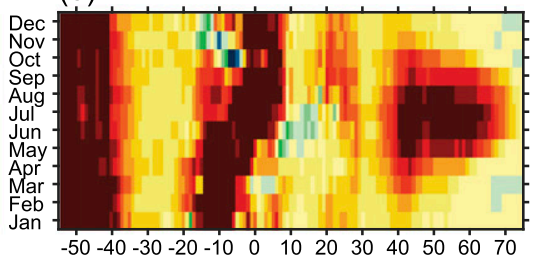

Latitude (Degree)

\begin{tabular}{cccccccccccccc}
\hline-2.4 & -1.8 & -1.2 & -0.6 & 0 & 0.6 & 1.2 & 1.8 & 2.4 & 3 & 3.6 & 4.2 & 4.8 & \\
& & & $\gamma_{\mathrm{Rh}}^{\top}$ & in the period $1982-2005\left(\mathrm{~g} \mathrm{C} \mathrm{m}^{-2} \mathrm{month}^{-1} \mathrm{~K}^{-1}\right)$ & &
\end{tabular}

FIG. 3. Spatial distributions of simulated monthly $\gamma_{\mathrm{Rh}}^{T}$ in the period 1982-2005; $\gamma_{\mathrm{Rh}}^{T}$ is estimated using Eq. (1). 
(a) Observation

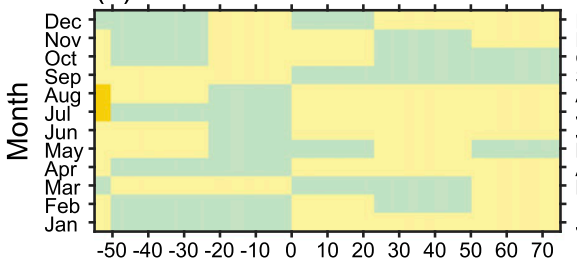

(d) CCSM 4

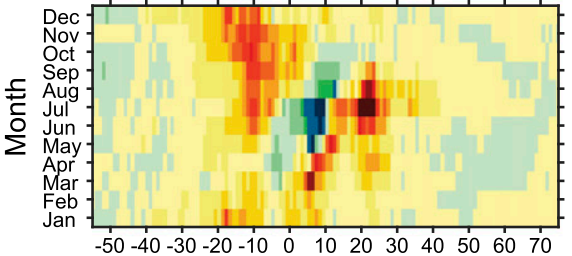

(g) GFDL-ESM2M

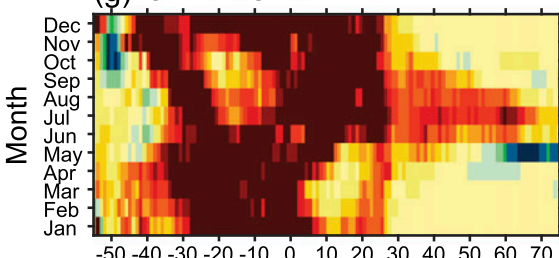

(j) IPSL-CM5A-LR

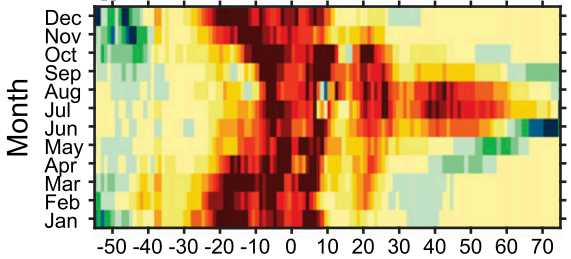

(m) MIROC-ESM-CHEM

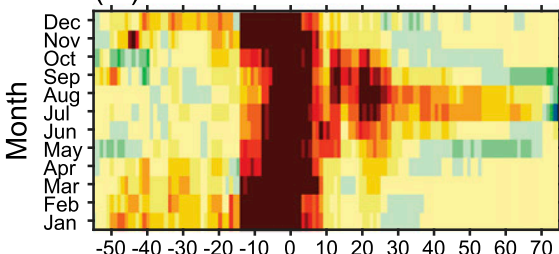

(p) MRI-ESM1

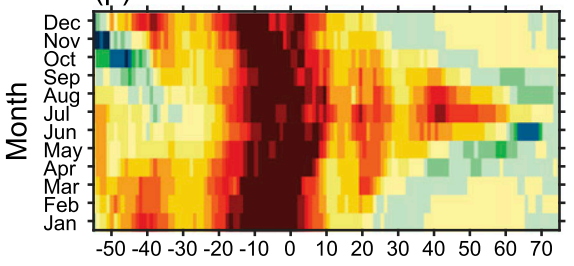

Latitude (Degree) (b) BNU-ESM

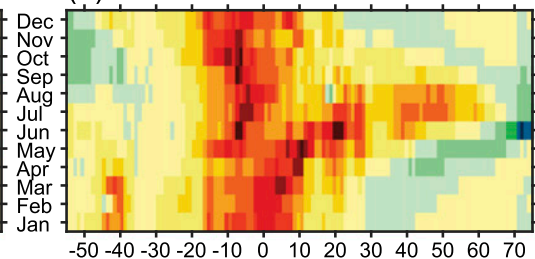

(e) CESM1-BGC

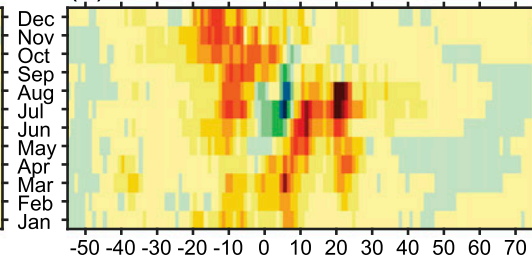

(h) HadGEM2-CC

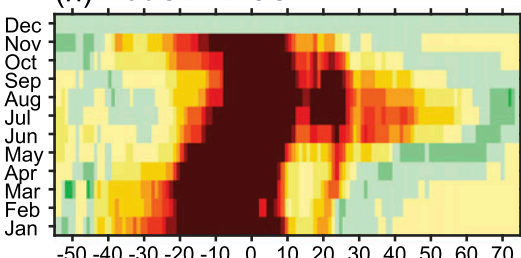

(k) IPSL-CM5B-LR

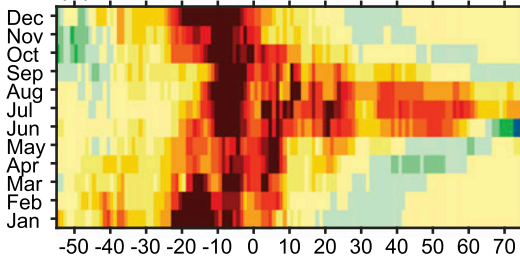

(n) MPI-ESM-LR

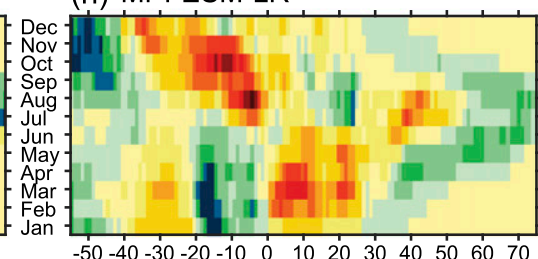

(q) NorESM1-M

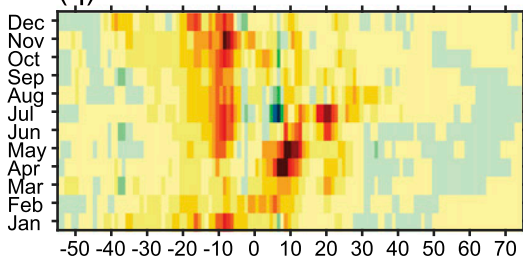
Latitude (Degree) (c) CanESM2

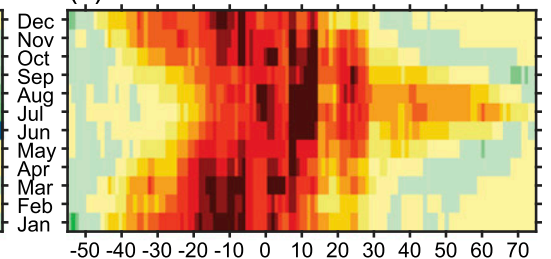

(f) GFDL-ESM2G

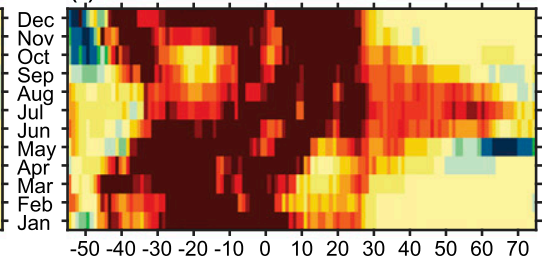

(i) HadGEM2-ES

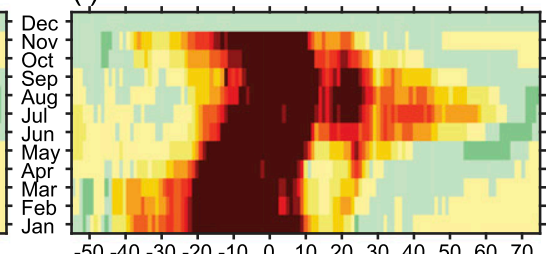

$-50-40-30-20-10 \quad 0 \quad 10 \quad 20 \quad 3040 \quad 50 \quad 6070$

(I) MIROC-ESM

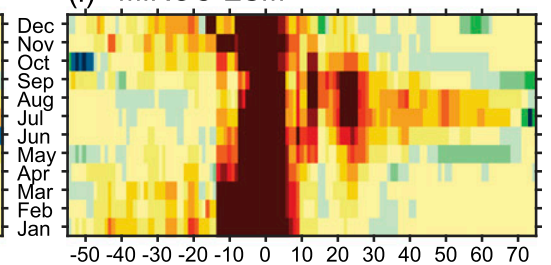

(o) MPI-ESM-MR

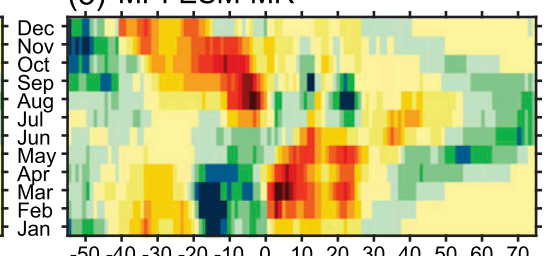

(r) NorESM1-ME

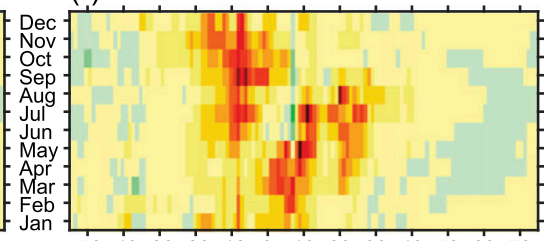

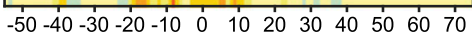
Latitude (Degree)

\begin{tabular}{|c|c|c|c|c|c|c|c|c|}
\hline-16 & -14 & -12 & -10 & -8 & -6 & -4 & -2 & 0 \\
\hline
\end{tabular}

FIG. 4. Spatial distributions of observed and simulated monthly $\gamma_{\mathrm{NBP}}^{T}$ in the period 1982-2005; $\gamma_{\mathrm{NBP}}^{T}$ is estimated using Eq. (1). 

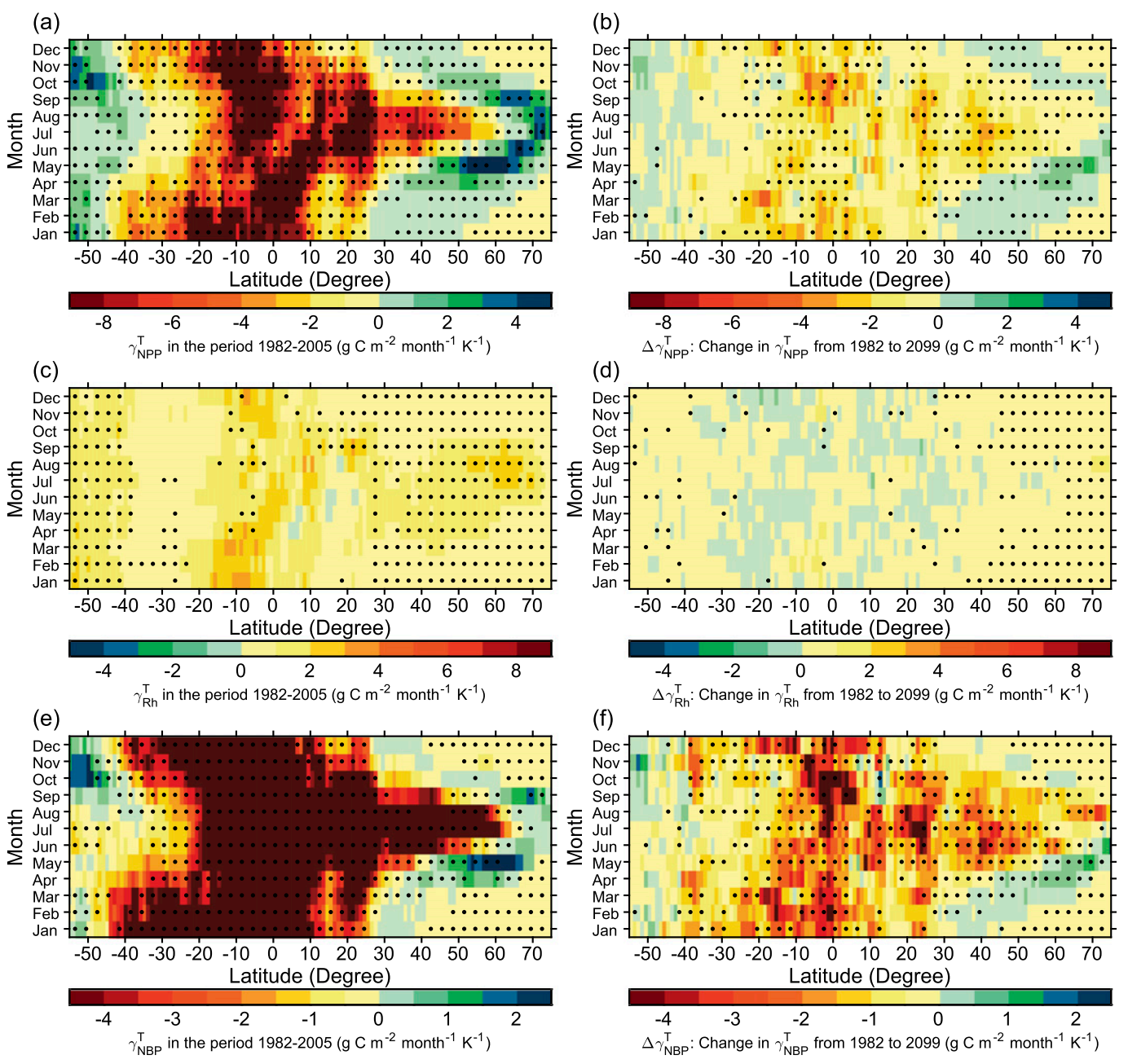

FIG. 5. Spatial distributions of multimodel median (a) $\gamma_{\mathrm{NPP}}^{T}$, (c) $\gamma_{\mathrm{Rh}}^{T}$, and (e) $\gamma_{\mathrm{NBP}}^{T}$, and (b),(d),(f) their respective changes from 1982 to 2099 under RCP4.5. Values of $\gamma_{\mathrm{NPP}}^{T}, \gamma_{\mathrm{Rh}}^{T}$, and $\gamma_{\mathrm{NBP}}^{T}$ are estimated using Eq. (1); $\Delta \gamma_{\mathrm{NPP}}^{T}, \Delta \gamma_{\mathrm{Rh}}^{T}$, and $\Delta \gamma_{\mathrm{NBP}}^{T}$ are calculated as the difference of $\gamma_{\mathrm{NPP}}^{T}, \gamma_{\mathrm{Rh}}^{T}$, and $\gamma_{\mathrm{NBP}}^{T}$, respectively, between the periods 2076-99 (RCP4.5 runs) and 1982-2005 (historical simulations). Black dots indicate significance at the 5\% level using a Wilcoxon signed-rank test. Models used are BNU-ESM, CanESM2, CCSM4, CESM1(BGC), GFDL-ESM2M, GFDL-ESM2G, HadGEM2-CC, HadGEM2-ES, IPSL-CM5A-LR, IPSL-CM5B-LR, MIROC-ESM, MIROCESM-CHEM, MPI-ESM-LR, MPI-ESM-MR, NorESM1-M, and NorESM1-ME.

from $-36.0_{-749}^{-1.8} \pm 9.5 \mathrm{TgCmonth}{ }^{-1} \mathrm{~K}^{-1}(p=0.015)$ in SON to $-10.5_{-27.7}^{16.7} \pm 2.3 \mathrm{TgCmonth}^{-1} \mathrm{~K}^{-1}(p=0.301)$ in DJF, rather than by generally nonsignificant $\Delta \gamma_{\mathrm{Rh}}^{T}$. Tropical surface air temperature in the period 20812100 increases by $1.6^{\circ} \mathrm{C}$ with respect to the $1986-2005$ reference period in CMIP5 ESMs under RCP4.5 (Collins et al. 2013). Parabolic responses of photosynthesis among $\mathrm{C}_{3}$ and $\mathrm{C}_{4}$ plants to temperature are incorporated in vegetation carbon models, as components of ESMs (Smith and Dukes 2013). Plant photosynthesis in tropical forests is therefore likely inhibited more severely by future warming, partly leading to the decreases of $\gamma_{\mathrm{NPP}}^{T}$ in ESMs. Furthermore, tropical lands are projected to become drier in CMIP5 ESMs (e.g., with decreasing soil moisture, and expansions of arid and semiarid areas) (Dai 2013; Feng and Fu 2013; Orlowsky and Seneviratne 2013; Scheff and Frierson 2015). Such water limitation likely contributes to the negative response of NPP to future warming in tropical forests. The changes in $\gamma_{\mathrm{NPP}}^{T}, \gamma_{\mathrm{Rh}}^{T}$, and $\gamma_{\mathrm{NBP}}^{T}$ are consistent across RCP2.6, RCP4.5, RCP6.0, and RCP8.5 but are more extreme under more intensive scenarios (Figs. S3-S12 in the supplemental material).

\section{2) TEMPERATE FORESTS}

Temperate forests are mainly distributed across northeastern North America, central Europe, and southeastern Asia (Fig. S2). In temperate forests, 
multimodel median $\gamma_{\mathrm{NBP}}^{T}$ is significant negative during 19822005 , ranging from $-47.0_{-52.0}^{-14.2} \pm 16.4 \mathrm{TgC}$ month $^{-1} \mathrm{~K}^{-1}$ $(p<0.001)$ in JJA to $-6.4_{-13.5}^{-1.0} \pm 7.1 \mathrm{TgCmonth}^{-1} \mathrm{~K}^{-1}$ $(p<0.001)$ in DJF (Fig. 1b). This negative NBP-T relationship was mainly contributed by negative $\gamma_{\mathrm{NPP}}^{T}$ in JJA, but by positive $\gamma_{R \mathrm{~h}}^{T}$ in MAM, SON, and DJF. Satellite-derived $\gamma_{\mathrm{NPP}}^{T}$ is nonsignificant in MAM, JJA, and DJF, but is positive in SON (22.7 \pm $\left.9.2 \mathrm{TgC} \mathrm{month}^{-1} \mathrm{~K}^{-1}, p=0.023\right)$. Inversion-based NBP is decoupled from $T$ in any season with nonsignificant $\gamma_{\mathrm{NBP}}^{T}$. Thus, both $\gamma_{\mathrm{NPP}}^{T}$ and $\gamma_{\mathrm{NBP}}^{T}$ in ESMs are inconsistent with the observation-based estimations over temperate forests.

The responses of temperate forests carbon cycle to climate variations have large spatial heterogeneity. In central Europe, the relation between tree-ring width and JJA temperature is nonsignificant in Mediterranean lowland regions, but is negative around the eastern part of the Mediterranean Sea (Babst et al. 2013). Across the eastern United States, photosynthesis increased because of warming-induced increases in growing season length (earlier spring and later autumn) that were larger than warming-induced increases in carbon release, resulting in positive responses of net carbon uptake to temperature (Keenan et al. 2014). In southern China, both the diameter at breast height of trees and the forest biomass decreased over the past three decades, partly due to warming (Zhou et al. 2013). Thus, temperate forest $\gamma_{\mathrm{NBP}}^{T}$ values may have spatially variable patterns, consistent with nonsignificant $\gamma_{\mathrm{NBP}}^{T}$ diagnosed at regional scale from the inversion. In contrast CMIP5 ESMs appear to generally overestimate the negative effect of $T$ on NBP in all seasons.

Over the twenty-first century, projected $\gamma_{\mathrm{NPP}}^{T}$ does not significantly change in all seasons except in SON with a multimodel median $\Delta \gamma_{\mathrm{NPP}}^{T}$ of $-10.9_{-18.7}^{0.7} \pm 2.9 \mathrm{TgC}$ month $^{-1} \mathrm{~K}^{-1}(p=0.001)$ under RCP4.5 (Fig. 1b), but it significantly decreases in MAM, JJA, and SON under RCP8.5, likely due to its relatively stronger warming (Fig. S5b). Under RCP4.5, $\gamma_{\mathrm{Rh}}^{T}$ increases significantly in SON with a multimodel median $\Delta \gamma_{\mathrm{Rh}}^{T}$ of $4.1_{1.9}^{9.2} \pm 2.1 \mathrm{TgCmonth}^{-1} \mathrm{~K}^{-1}(p=0.001)$ but does not change in the other seasons (Fig. 1b). Because of both the decrease in $\gamma_{\mathrm{NPP}}^{T}$ and increase in $\gamma_{\mathrm{Rh}}^{T}$, projected $\gamma_{\mathrm{NBP}}^{T}$ decrease significantly with a multimodel median $\Delta \gamma_{\mathrm{Rh}}^{T}$ of $4.1_{1.9}^{9.2} \pm$ 2.1 $\mathrm{TgCmonth}^{-1} \mathrm{~K}^{-1}(p=0.001)$ in SON under RCP4.5.

\section{3) BOREAL FORESTS}

In boreal forests, there is clear seasonal difference in $\gamma_{\mathrm{NPP}}^{T}$ and $\gamma_{\mathrm{NBP}}^{T}$ during the past 30 years in ESMs (Figs, $1 \mathrm{c}, 2,4$, and 5a,e). The multimodel median $\gamma_{\mathrm{NBP}}^{T}$ in MAM is $13.0_{11.3}^{16.2} \pm 4.0 \mathrm{TgCmonth}^{-1} \mathrm{~K}^{-1}$ during 1982 2005 ( $p<0.001)$, indicating more $\mathrm{CO}_{2}$ uptake during warmer years, which is comparable with the inversionbased $\gamma_{\mathrm{NBP}}^{T}$ of $18.5 \pm 5.5 \mathrm{TgC}$ month ${ }^{-1} \mathrm{~K}^{-1}(p=0.003)$ (Fig. 1c). Such positive NBP-T relation is mainly dominated by the positive $\gamma_{\mathrm{NPP}}^{T}$ of $20.8_{18.1}^{27.7} \pm 4.4 \mathrm{TgCmonth}{ }^{-1} \mathrm{~K}^{-1}$ $(p<0.001)$ in ESMs, which is consistent with the satellitederived $\gamma_{\mathrm{NPP}}^{T}\left(16.8 \pm 4.0 \mathrm{TgCmonth}^{-1} \mathrm{~K}^{-1}, p<0.001\right)$. Plant photosynthesis in boreal forests is likely limited by low temperature in the Northern Hemisphere $(\mathrm{NH})$ spring, and is therefore enhanced by spring warming. Warming partly led to advance in spring and delay in autumn in the $\mathrm{NH}\left(>30^{\circ} \mathrm{N}\right)$ in the past three decades (Piao et al. 2007; Richardson et al. 2010). The start of the growing season in the $\mathrm{NH}$ comes earlier under climate warming background in ESMs (Xia et al. 2015). Vegetation growth in ESMs is enhanced by a warmer spring, resulting in positive response of seasonal vegetation activity to $T$ (Wu et al. 2016). Rh in MAM is also positively related with $T$ in ESMs, with a multimodel median $\gamma_{\mathrm{Rh}}^{T}$ of $10.3_{7.1}^{13.9} \pm 1.7 \mathrm{TgC}$ month $^{-1} \mathrm{~K}^{-1}$ $(p<0.001)$, which is lower than $\gamma_{\mathrm{NPP}}^{T}$, resulting in a positive $\gamma_{\mathrm{NBP}}^{T}$ in MAM.

In JJA, NPP is decoupled from $T$ in ESMs, and satellite-derived $\gamma_{\mathrm{NPP}}^{T}$ is marginally significant $(25.0 \pm$ 12.4 TgC month ${ }^{-1} \mathrm{~K}^{-1}, p=0.058$ ) (Fig. 1c). Multimodel median $\gamma_{\mathrm{NBP}}^{T}$ in JJA is $-33.8_{-76.7}^{-5.8} \pm 16.7 \mathrm{TgCmonth}^{-1} \mathrm{~K}^{-1}$ $(p<0.001)$, which is less negative than the inversion-based $\gamma_{\mathrm{NBP}}^{T}$ value of $-79.4 \pm 30.7 \mathrm{TgCmonth}^{-1} \mathrm{~K}^{-1}(p=0.018)$. Such negative NBP-T relationships in both ESMs and inversion-based estimations are dominated by the positive values of $\gamma_{\mathrm{Rh}}^{T}$. Water, rather than temperature, is a major limitation factor for the summer growth of boreal forests. For instance, in central Eurasia, boreal forests become exposed to drier conditions because of warmer summers without a coincident increase in precipitation during the past three decades (Buermann et al. 2014). Compared with inversion-based $\gamma_{\mathrm{NBP}}^{T}$ in summer, most CMIP5 ESMs appear to underestimate the negative effects of $T$ on net carbon uptake. This discrepancy could be due to missing or underrepresented temperature response processes and mechanisms in ESMs. For example, warming-induced drought was found to increase tree mortality-a missing process in ESMs-across Canada's boreal forests from 1963 to 2008 (Peng et al. 2011) and therefore contributed to a reduction in carbon sink strength (Ma et al. 2012).

In SON, satellite-derived $\gamma_{\mathrm{NPP}}^{T}$ is significantly positive with value of $10.3 \pm 2.2 \mathrm{TgC} \mathrm{month}^{-1} \mathrm{~K}^{-1}(p<0.001)$, which is captured by ESMs giving a multimodel median $7.8_{3.5}^{11.5} \pm 3.3 \mathrm{TgC}$ month $^{-1} \mathrm{~K}^{-1}(p<0.001)$ (Fig. 1c). Such positive responses of NPP to $T$ may be partly attributed to the warming-induced delay in autumn over the past three decades (Garonna et al. 2016; Q. Liu et al. 
2016), which however, remains to be evaluated in ESMs. In ESMs, the positive $\gamma_{\mathrm{NPP}}^{T}$ is cancelled by the positive $\gamma_{\mathrm{Rh}}^{T}\left(10.0_{5.4}^{14.1} \pm 2.6 \mathrm{TgC}\right.$ month $\left.^{-1} \mathrm{~K}^{-1}, p<0.001\right)$, resulting in nonsignificant $\gamma_{\mathrm{NBP}}^{T}$. Autumn NBP in boreal forests is also almost decoupled from $T$ in inversion-based estimations with $\gamma_{\mathrm{NBP}}^{T}$ of $-8.8 \pm 5.1 \mathrm{TgC}$ month $^{-1} \mathrm{~K}^{-1}$ $(p=0.103)$.

Future changes in $\gamma_{\mathrm{NBP}}^{T}$ in boreal forests mainly depend on the balance between changes in $\gamma_{\mathrm{NPP}}^{T}$ and $\gamma_{\mathrm{Rh}}^{T}$. By the end of the twenty-first century, the changes in responses of NBP to $T$ in boreal forests are seasonspecific in ESMs under RCP4.5 (Fig. 1c). In MAM, $\Delta \gamma_{\mathrm{NPP}}^{T}$ and $\Delta \gamma_{\mathrm{Rh}}^{T}$ are comparable with multimodel median of $4.7_{-1.8}^{17.0} \pm 1.2(p=0.03)$ and $4.6_{0.8}^{10.7} \pm$ $0.8 \mathrm{TgC}$ month $^{-1} \mathrm{~K}^{-1}(p=0.002)$, respectively, leading to nonsignificant $\Delta \gamma_{\mathrm{NBP}}^{T}$ under RCP4.5 (Fig. 1c). But under RCP8.5, $\gamma_{\mathrm{NBP}}^{T}$ in MAM significantly increases with a multimodel median $\Delta \gamma_{\mathrm{NBP}}^{T}$ of $9.3_{2.2}^{21.5} \pm$ $1.6 \mathrm{TgC}$ month ${ }^{-1} \mathrm{~K}^{-1}(p=0.003)$, mainly contributed by $\Delta \gamma_{\mathrm{NPP}}^{T}\left(21.5_{10.6}^{34.9} \pm 1.3 \mathrm{TgC} \mathrm{month}^{-1} \mathrm{~K}^{-1}, p=0.001\right)$ being more positive than $\Delta \gamma_{\mathrm{Rh}}^{T}\left(10.8_{1.1}^{15.3} \pm\right.$ 1.4 TgC month ${ }^{-1} \mathrm{~K}^{-1}, p=0.002$ ) (Fig. S5c). Compared with the 1986-2005 reference period, projected Arctic surface air temperature in the period 2081-2100 will increase by $4.2^{\circ} \mathrm{C}$ under RCP4.5 and $8.3^{\circ} \mathrm{C}$ under RCP8.5 (Collins et al. 2013). Future warming may enhance vegetation growth via stimulating plant photosynthesis and advancing spring, with carbon uptake comparable or greater than the warming-induced increase in carbon release via $\mathrm{Rh}$. High warming, however, may reduce plant growth in $\mathrm{NH}$ summer (e.g., JJA). The multimodel median $\Delta \gamma_{\mathrm{NPP}}^{T}$ in JJA is $-10.4_{-43.1}^{-0.6} \pm 5.7 \mathrm{TgCmonth}{ }^{-1} \mathrm{~K}^{-1}(p=$ 0.026 ), indicating a decrease of interannual NPP sensitivity in summer, resulting in a decrease in $\gamma_{\mathrm{NBP}}^{T}$ with $\Delta \gamma_{\mathrm{NBP}}^{T}$ of $-27.0_{-568}^{2.7} \pm 6.9 \mathrm{TgCmonth}^{-1} \mathrm{~K}^{-1}(p=0.02)$ under RCP4.5 (Fig. 1c). The negative $\Delta \gamma_{\mathrm{NPP}}^{T}$ may be partly due to drought intensification in boreal regions by the end of twenty-first century. In CMIP5 ESMs, soil moisture is projected to decrease in boreal regions over the twentyfirst century, particular in JJA (Dai 2013). In SON, both projected $\Delta \gamma_{\mathrm{NPP}}^{T}\left(-2.4_{-5.6}^{1.3} \pm 5.7 \mathrm{TgCmonth}{ }^{-1} \mathrm{~K}^{-1}\right.$, $p=0.163)$ but $\Delta \gamma_{\mathrm{Rh}}^{T}\left(1.1_{-1.0}^{4.1} \pm 1.6 \mathrm{TgCmonth}^{-1} \mathrm{~K}^{-1}\right.$, $p=0.179$ ) are nonsignificant, but leading to significant decreases in $\gamma_{\mathrm{NBP}}^{T}$ with $\Delta \gamma_{\mathrm{NBP}}^{T}$ of $-4.0_{-6.9}^{-1.3} \pm$ $1.7 \mathrm{TgC}$ month ${ }^{-1} \mathrm{~K}^{-1}(p=0.007)$ (Fig. 1c). Compared with RCP4.5, under the other RCPs (RCP2.6, RCP6.0, and $\mathrm{RCP} 8.5), \Delta \gamma_{\mathrm{NPP}}^{T}, \Delta \gamma_{\mathrm{Rh}}^{T}$, and $\Delta \gamma_{\mathrm{NBP}}^{T}$ are consistent but greater in more intensive scenarios (Figs. S3-S12).

\section{4) SEMIARID ECOSYSTEMS}

In semiarid ecosystems, multimodel median $\gamma_{\mathrm{NBP}}^{T}$ range from $-130.2_{-188.0}^{-94.9} \pm 53.3 \mathrm{TgC}$ month ${ }^{-1} \mathrm{~K}^{-1}(p<$ $0.001)$ in SON to $-86.0_{-218.9}^{-29.6} \pm 56.9 \mathrm{TgCmonth}^{-1} \mathrm{~K}^{-1}$ $(p<0.001)$ in MAM, mainly due to the negative responses of NPP to $T$ in all seasons (Fig. 1d). Satellite-derived $\gamma_{\text {NPP }}^{T}$ is also negative at $-147.6 \pm 39.6 \mathrm{TgC}$ month $^{-1} \mathrm{~K}^{-1}(p=$ 0.001 ) in MAM but is slightly more negative than the ESMs simulations $\left(-109.7_{-187.9}^{-17.4} \pm 55.4 \mathrm{TgC}_{\text {month }}{ }^{-1} \mathrm{~K}^{-1}\right.$, $p<0.001)$. Satellite-derived $\gamma_{\mathrm{NPP}}^{T}$ is nonsignificant in JJA, SON, and DJF. Inversion-based NBP is significantly related to $T$ in MAM and SON with $\gamma_{\mathrm{NBP}}^{T}$ of $-179.9 \pm$ $54.1(p=0.003)$ and $-76.5 \pm 34.5 \mathrm{TgCmonth}^{-1} \mathrm{~K}^{-1}(p=$ $0.038)$, respectively. But inversion-based $\gamma_{\mathrm{NBP}}^{T}$ is nonsignificant in JJA and DJF. Compared with the observation-based estimations, CMIP5 ESMs seem to underestimate the negative influence of warmer years on NBP in MAM (dry season in the northern tropics and subtropics) but overestimate the warming-induced suppression of NBP in the other seasons.

Semi-arid ecosystems in this analysis are mainly dominated by shrublands and savannas, mainly distributed across the subtropics in the Southern Hemisphere (SH), for example, southern South America, southern Africa, and Australia (Fig. S1). In most of these regions, weather could be generally divided into two main seasons: the rainy season (approximately November-April), and the dry season (approximately May-October). Vegetation phenology is mainly controlled by terrestrial hydrological variability, rather than temperature variations in the semiarid ecosystems [e.g., savannas in northern Australia (Ma et al. 2013) and Africa (Guan et al. 2014)]. Inversion-based $\gamma_{\mathrm{NBP}}^{T}$ are season-specific, probably partly due to the seasonspecific vegetation growth under various hydrological conditions. In the SH subtropics, SON and MAM are transitional periods of dry season to rainy season and rainy season to dry season, respectively, corresponding to the beginning and end of phenology of deciduous species. Compared with MAM and SON, canopy cover is much lower in that in JJA, particularly for fully deciduous species (Williams et al. 1997). Thus, the relative larger response of satellite-derived NPP to $T$ in MAM may be partly due to the greater leaf photosynthetic substrate (canopy biomass) than that in JJA, SON, and DJF, leading to greatest $\gamma_{\mathrm{NBP}}^{T}$ in MAM.

Over the twenty-first century, in semiarid ecosystems, projected $\gamma_{\mathrm{NPP}}^{T}$ marginally significantly decreases in MAM under RCP4.5 with multimodel median $\Delta \gamma_{\mathrm{NPP}}^{T}$ of $-27.2_{-75.5}^{22.0} \pm 18.5 \mathrm{TgC}_{\text {month }}{ }^{-1} \mathrm{~K}^{-1}(p=0.07)$ in MAM but do not significantly change in the other seasons (Fig. 1d). Similarly, the projected $\gamma_{\mathrm{NBP}}^{T}$ does not significantly change in most seasons, suggesting that $\Delta \gamma_{\mathrm{NPP}}^{T}$ is partly offset by $\Delta \gamma_{\mathrm{Rh}}^{T}$ (reductions of Rh in warmer years) For instance, projected $\gamma_{\mathrm{Rh}}^{T}$ decreases by $-13.1_{-34.1}^{3.0} \pm$ $11.1 \mathrm{TgC}$ month ${ }^{-1} \mathrm{~K}^{-1}(p=0.03)$ in MAM (i.e., less respiration in warmer years), which cancel out nearly 
half of $\Delta \gamma_{\mathrm{NPP}}^{T}$, resulting in insignificant $\Delta \gamma_{\mathrm{NBP}}^{T}$. The decrease in $\gamma_{\mathrm{NPP}}^{T}$ might be due to both projected warming and exacerbated drought. CMIP5 ESMs projected soil moisture dramatically decreases in $\mathrm{SH}$ subtropics in all seasons over the twenty-first century under RCP4.5 (Dai 2013). In dry ecosystems, projected NPP interannual sensitivity is particularly sensitive to the drought-induced intensity of the dry season by the end of the twenty-first century compared with other biomes (Murray-Tortarolo et al. 2016). Different from the nonsignificant $\Delta \gamma_{\mathrm{NBP}}^{T}$ under RCP4.5, $\Delta \gamma_{\mathrm{NBP}}^{T}$ under RCP8.5 is negative because of decreases in $\gamma_{\mathrm{NPP}}^{T}$ across ESMs (Fig. S4).

\section{5) GRASSLAndS}

There are large differences in $\gamma_{\mathrm{NBP}}^{T}$ between ESMs and inversion-based estimations during 1982-2005 (Fig. 1e). In MAM, the multimodel median $\gamma_{\mathrm{NPP}}^{T}$ is $14.2_{3.8}^{34.9} \pm$ 10.0 TgC month ${ }^{-1} \mathrm{~K}^{-1}(p<0.001)$, that is, higher NPP in warmer years, which is comparable with the satellite-derived $\gamma_{\mathrm{NPP}}^{T}$ of $16.3 \pm 6.3 \mathrm{TgCmonth}^{-1} \mathrm{~K}^{-1}$ $(p=0.018)$. Simulated $\gamma_{\mathrm{NPP}}^{T}$ is largely offset by $\gamma_{\mathrm{Rh}}^{T}$ $\left(9.3_{2.3}^{14.6} \pm 5.5 \mathrm{TgCmonth}^{-1} \mathrm{~K}^{-1}, p<0.001\right)$, leading to marginally significant $\gamma_{\mathrm{NBP}}^{T}\left(8.3_{-3.9}^{18.6} \pm 10.0 \mathrm{TgCmonth}^{-1} \mathrm{~K}^{-1}\right.$, $p=0.1)$ in MAM in ESMs. Thus, compared with the inversion-based $\gamma_{\mathrm{NBP}}^{T}$ of $40.4 \pm 10.4 \mathrm{TgCmonth}{ }^{-1} \mathrm{~K}^{-1}$ $(p=0.001)$ in MAM, ESMs underestimate grassland $\gamma_{\mathrm{NBP}}^{T}$. Different from positive $\gamma_{\mathrm{NBP}}^{T}$ in MAM, NBP in JJA is negatively related with $T$ in ESMs, with multimodel median $\gamma_{\mathrm{NBP}}^{T}$ of $-62.1_{-79.7}^{-38.4} \pm 29.7 \mathrm{TgCmonth}{ }^{-1} \mathrm{~K}^{-1}(p<$ $0.001)$, becaue of both negative $\gamma_{\mathrm{NPP}}^{T}\left(-42.0_{-64.7}^{-22.4} \pm\right.$ 33.0 TgCmonth $\left.{ }^{-1} \mathrm{~K}^{-1}, p<0.001\right)$ and positive $\gamma_{\mathrm{Rh}}^{T}$ $\left(11.2_{5.5}^{28.4} \pm 12.5 \mathrm{TgCmonth}^{-1} \mathrm{~K}^{-1}, p<0.001\right)$. Both satellite-derived NPP and inversion-based NBP are decoupled from $T$ in JJA, but are positively related with $T$ in SON with $\gamma_{\mathrm{NPP}}^{T}$ of $9.7 \pm 4.2 \mathrm{TgCmonth}^{-1} \mathrm{~K}^{-1}(p=$ $0.03)$ and $\gamma_{\mathrm{NBP}}^{T}$ of $19.3 \pm 9.2 \mathrm{TgCmonth}^{-1} \mathrm{~K}^{-1}(p=0.049)$, respectively. In contrast, SON $\gamma_{\mathrm{NBP}}^{T}$ in ESMs is negative because of both positive $\gamma_{\mathrm{Rh}}^{T}$ and nonsignificant $\gamma_{\mathrm{NPP}}^{T}$.

Grasslands in this analysis are mainly distributed in the NH midlatitudes, for example, the western United States, central Asia, Mongolia, and northern and western China (Fig. S1). In these regions, temperature in MAM and SON is much lower than the optimum temperature for photosynthesis. Warming, therefore, probably increases plant growth in MAM and SON during warmer years over the past three decades. Such positive responses of grasslands NPP to $T$ may also be partly due to elevated atmosphere $\mathrm{CO}_{2}$ concentration. It seems that the positive $\gamma_{\mathrm{NPP}}^{T}$ is not likely due to changes in phenology during the past three decades since no generally changes in the phenology in grasslands have been observed (Zhao et al. 2015) and phenology probably is mainly influenced by precipitation rather than temperature in water-limited grasslands $(\mathrm{Q}$. Liu et al. 2016; Shen et al. 2015). It is worth noting that the inversion-based $\gamma_{\mathrm{NBP}}^{T}$ is much higher than the satellitederived $\gamma_{\mathrm{NPP}}^{T}$ in both MAM and SON, and therefore, maybe overestimated.

In JJA, grasslands carbon uptake is limited by water rather than temperature, for example, in western United States (Gang et al. 2015; Gremer et al. 2015) and northern China (Gang et al. 2015; Shen et al. 2016). Thus, satellitederived NPP is decoupled from $T$, leading to nonsignificant $\gamma_{\mathrm{NBP}}^{T}$ (Fig. 1e). While grasslands NPP is negatively related to $T$ in ESMs in JJA. $\gamma_{\mathrm{NPP}}^{T}$ in JJA are projected to decease over the twenty-first century under RCP4.5, with multimodel median $\Delta \gamma_{\mathrm{NPP}}^{T}$ of $-36.1_{-120.4}^{-22.9} \pm$ 14.3 $\mathrm{TgC} \mathrm{month}^{-1} \mathrm{~K}^{-1}(p=0.001)$, leading to more negative $\gamma_{\mathrm{NBP}}^{T}\left(-45.4_{-94.3}^{-30.3} \pm 11.7 \mathrm{TgC} \mathrm{month}^{-1} \mathrm{~K}^{-1}\right.$, $p=0.001$ ). This is probably because grasslands are projected to become drier in summer over the twentyfirst century under RCP4.5 (Dai 2013). Such severe drought could reduce fractional cover of grasslands in summer (Hufkens et al. 2016), resulting in decreases in $\gamma_{\mathrm{NPP}}^{T}$ and $\gamma_{\mathrm{NBP}}^{T}$. This phenomenon is consistent across RCP2.6, RCP4.5, RCP6.0, and RCP8.5 (Fig. 1e; see also Figs S3e, S4e, and S5e).

\section{6) SHRUblandS AND SUbARCTIC ECOSYSTEMS}

The shrublands and subarctic ecosystems in this study mainly include natural vegetation (except forests) at latitudes north of $50^{\circ} \mathrm{N}$. Satellite-derived NPP is positively related with $T$ across all seasons except DJF, with the $\gamma_{\mathrm{NPP}}^{T}$ being $5.7 \pm 1.4 \mathrm{TgCmonth}{ }^{-1} \mathrm{~K}^{-1}(p=0.001)$ in MAM, 50.6 $\pm 8.9 \mathrm{TgCmonth}^{-1} \mathrm{~K}^{-1}(p<0.001)$ in JJA, and $4.7 \pm 1.1 \mathrm{TgCmonth}^{-1} \mathrm{~K}^{-1}(p=0.001)$ in SON (Fig. 1f). ESMs capture the positive $\gamma_{\mathrm{NPP}}^{T}$ with multimodel median $\gamma_{\mathrm{NPP}}^{T}$ of $9.6_{6.6}^{17.9} \pm 3.4 \mathrm{TgC}$ month ${ }^{-1} \mathrm{~K}^{-1}(p<0.001)$ in MAM, 63. $1_{6.3}^{85.0} \pm 15.6 \mathrm{TgCmonth}^{-1} \mathrm{~K}^{-1}(p<0.001)$ in $\mathrm{JJA}$, and $6.6_{3.1}^{9.2} \pm 2.5 \mathrm{TgC}$ month $^{-1} \mathrm{~K}^{-1}(p<0.001)$ in SON, respectively. In ESMs, the $\gamma_{\mathrm{NPP}}^{T}$ in MAM was partly offset by $\gamma_{\mathrm{Rh}}^{T}$, leading to $\gamma_{\mathrm{NBP}}^{T}$ of $3.8_{1.9}^{9.1} \pm$ $2.9 \mathrm{TgCmonth}^{-1} \mathrm{~K}^{-1}(p<0.001)$. In JJA, NBP in ESMs is nearly decoupled from $T$, because $\gamma_{\mathrm{NPP}}^{T}$ and $\gamma_{\mathrm{Rh}}^{T}$ cancel each other out. In SON and DJF, $\gamma_{\mathrm{NBP}}^{T}$ is significantly negative with multimodel median $\gamma_{\mathrm{NBP}}^{T}$ of $-1.4_{-4.6}^{0.0} \pm 2.6(p<0.001)$ and $-2.9_{-4.1}^{-1.5} \pm$ $1.2 \mathrm{TgC} \mathrm{month}^{-1} \mathrm{~K}^{-1}(p<0.001)$, respectively, which are mainly dominated by positive $\gamma_{\mathrm{Rh}}^{T}$ rather than $\gamma_{\mathrm{NPP}}^{T}$. The inversion-based $\gamma_{\mathrm{NBP}}^{T}$ is nonsignificant across all seasons.

Arctic regions have been subject to strong nearsurface warming during past recent decades, which is almost twice the global average (Graversen et al. 2008; Hartmann et al. 2013). This warming signal extended the growing season of ecosystems at northern high latitudes 
via advancing spring (Hoye et al. 2007; Parmesan 2006). Meanwhile, the photosynthetic rate in subarctic ecosystems is limited by relatively low temperature, and could be enhanced by warming, thus enhancing NPP. Furthermore, multiple lines of evidence demonstrate that both the abundance and extent of shrubs increased in subarctic regions caused by warming during past recent decades (Elmendorf et al. 2012; Myers-Smith et al. 2011; Sturm et al. 2001; Tape et al. 2006). Such changes in subarctic vegetation structure may also contribute to the positive satellite-derived $\gamma_{\mathrm{NPP}}^{T}$, but remain to be evaluated in ESMs.

By the end of the twenty-first century, projected $\gamma_{\mathrm{NBP}}^{T}$ becomes more positive in MAM with multimodel median $\Delta \gamma_{\mathrm{NBP}}^{T}$ of $4.6_{1.2}^{13.4} \pm 2.1 \mathrm{TgC}$ month $^{-1} \mathrm{~K}^{-1}(p=$ $0.003)$, and decreases in JJA and DJF with multimodel median $\Delta \gamma_{\mathrm{NBP}}^{T}$ of $-13.6_{-68.8}^{0.0} \pm 9.0(p=0.017)$ and $-2.1_{-4.2}^{-0.5} \pm 0.7 \mathrm{TgCmonth}{ }^{-1} \mathrm{~K}^{-1}(p=0.004)$, respectively, but does not change in SON under RCP4.5 (Fig. 1f). Such changes in $\gamma_{\mathrm{NBP}}^{T}$ mainly depend on changes in $\gamma_{\mathrm{NPP}}^{T}$ and $\gamma_{\mathrm{Rh}}^{T}$. Projected $\gamma_{\mathrm{NPP}}^{T}$ increases in MAM and SON with multimodel median $\Delta \gamma_{\mathrm{NPP}}^{T}$ of $10.7_{3.8}^{18.2} \pm 2.4(p<$ $0.001)$ and $3.5_{-1.4}^{7.1} \pm 0.7 \mathrm{TgCmonth}^{-1} \mathrm{~K}^{-1}(p<0.001)$, respectively, but does not significantly change in JJA under RCP4.5 (Fig. 1f). Note that $\gamma_{\mathrm{Rh}}^{T}$ becomes more positive in all seasons under RCP4.5, with multimodel median $\Delta \gamma_{\mathrm{Rh}}^{T}$ ranging from $2.0_{05}^{4.5} \pm 0.4 \mathrm{TgC}$ month $^{-1} \mathrm{~K}^{-1}$ $(p=0.001)$ in DJF to $15.6_{0.6}^{38.8} \pm 5.6 \mathrm{TgCmonth}^{-1} \mathrm{~K}^{-1}$ $(p=0.011)$ in JJA. The seasonal patterns of $\Delta \gamma_{\mathrm{NPP}}^{T}, \Delta \gamma_{\mathrm{Rh}}^{T}$, and $\Delta \gamma_{\mathrm{NBP}}^{T}$ are consistent across RCPs, but are more apparent under more intensive scenarios, particularly in RCP8.5 (Figs. S3-S12).

Changes in both $\gamma_{\mathrm{NPP}}^{T}$ and $\gamma_{\mathrm{Rh}}^{T}$ are likely due to the dramatic warming in the twenty-first century projected by ESMs. Future dramatic warming could extend growing seasons (Ruosteenoja et al. 2016) and raise photosynthetic rates, and therefore increase $\gamma_{\mathrm{NPP}}^{T}$ in ESMs. The projected increasingly positive $\gamma_{\mathrm{Rh}}^{T}$ across models is likely due to warming-induced increases in $\mathrm{Rh}$ rates (Todd-Brown et al. 2013) and organic carbon storage (Todd-Brown et al. 2014) in NH high latitudes. It is noteworthy that the permafrost carbon dynamics are not explicitly represented in CMIP5 ESMs (Schuur et al. 2015; Todd-Brown et al. 2014), resulting in large uncertainty in projection of $\Delta \gamma_{\mathrm{Rh}}^{T}$. Microbial processes are key biogeochemical mechanisms that have been shown to control the sign of the effect of future warming on soil carbon storage (Wieder et al. 2013). In addition, future climate change may increase the vulnerability of subarctic ecosystems to fire, because of drier soils and increases in lightning ignitions caused by warming (Turetsky et al. 2015). To better project the responses of carbon cycles to future climate change, we recommend that the mechanism underlying the effects of northern latitude fire on the carbon cycle and their feedbacks to the climate system should be fully considered in the next generation of ESMs.

\section{b. Interannual precipitation sensitivities of seasonal carbon fluxes}

In most ESMs, NPP is positively related with $P$ across all biomes (except in shrublands and subarctic ecosystems), particularly in tropical forests and semiarid ecosystems, where $\gamma_{\mathrm{NPP}}^{P}$ is significantly positive in all seasons during 1982-2005 (Figs. 6 and S13 in the supplemental material). This is probably because plant growth in tropical and subtropical regions is limited by water because of drought or above-optimal temperature in ESMs. The value of $\gamma_{\mathrm{NPP}}^{P}$ in models is generally positive in both $\mathrm{NH}$ tropics and $\mathrm{SH}$ tropics, but with different strength in different month. Specifically, in NH tropics, $\gamma_{\mathrm{NPP}}^{P}$ in November-April is much more positive than that $\gamma_{\mathrm{NPP}}^{P}$ in the other months. But in SH tropics, $\gamma_{\mathrm{NPP}}^{P}$ is much more positive in May-October compared to the other months. This is probably because the dry season occurs at different times in the NH tropics (approximately November-April) and SH tropics (approximately MayOctober) resulting from the intertropical convergence zone (ITCZ) movement. Drought is also likely to occur in temperate and boreal forests, and grasslands in NH summer with positive $\gamma_{\mathrm{NPP}}^{P}$ in MAM in ESMs. The value of $\gamma_{\mathrm{NBP}}^{P}$ in ESMs depends on both responses of NPP and $\mathrm{Rh}$ to $P$, but varies with ESMs (Figs. 6-9).

Satellite-derived NPP is generally decoupled from $P$ in most seasons, partly leading to nonsignificant inversionbased $\gamma_{\mathrm{NBP}}^{P}$ (Figs. 6, 7a, and 9a). The decoupling between interannual variations in aboveground NPP and precipitation is also found across 11 Long Term Ecological Research network sites across North America covering forests and grasslands (Knapp and Smith 2001). This is probably because the interannual variations of precipitation are negatively related to precipitation amount (e.g., large in drier relative to more mesic regions) (Fatichi et al. 2012). The responses of NPP to $P$ depend on both biotic (e.g., plant species and leaf areas) and abiotic factors (e.g., the strength of interannual variations in precipitation). Although humid and semihumid ecosystems (e.g., forests) have greater leaf areas and faster growing species, NPP responses are constrained by weak precipitation variations (Knapp and Smith 2001). In contrast, arid and semiarid ecosystems experience relatively large precipitation variations, but NPP responses are constrained by low plant density and leaf area (Knapp and Smith 2001). Therefore, satellite-derived $\gamma_{\mathrm{NPP}}^{P}$ is nonsignificant in most seasons across all biomes (Fig. 6). However, a global meta-analysis shows that interannual variations in aboveground NPP are positively related to 
(a) Tropical forests

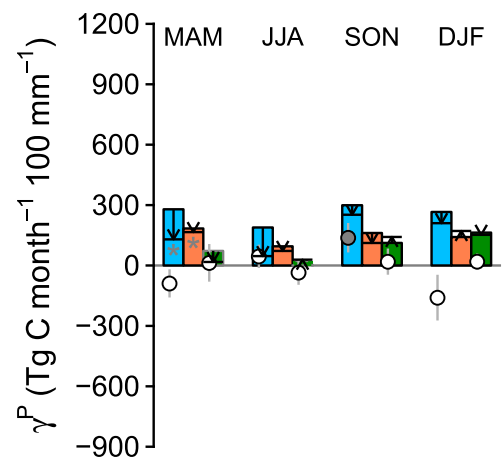

(d) Semi-arid ecosystems (b) Temperate forests

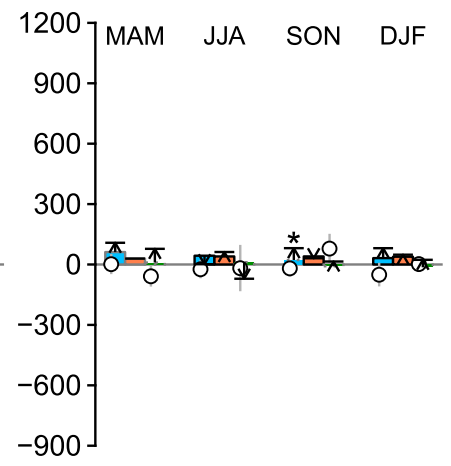

(e) Grasslands

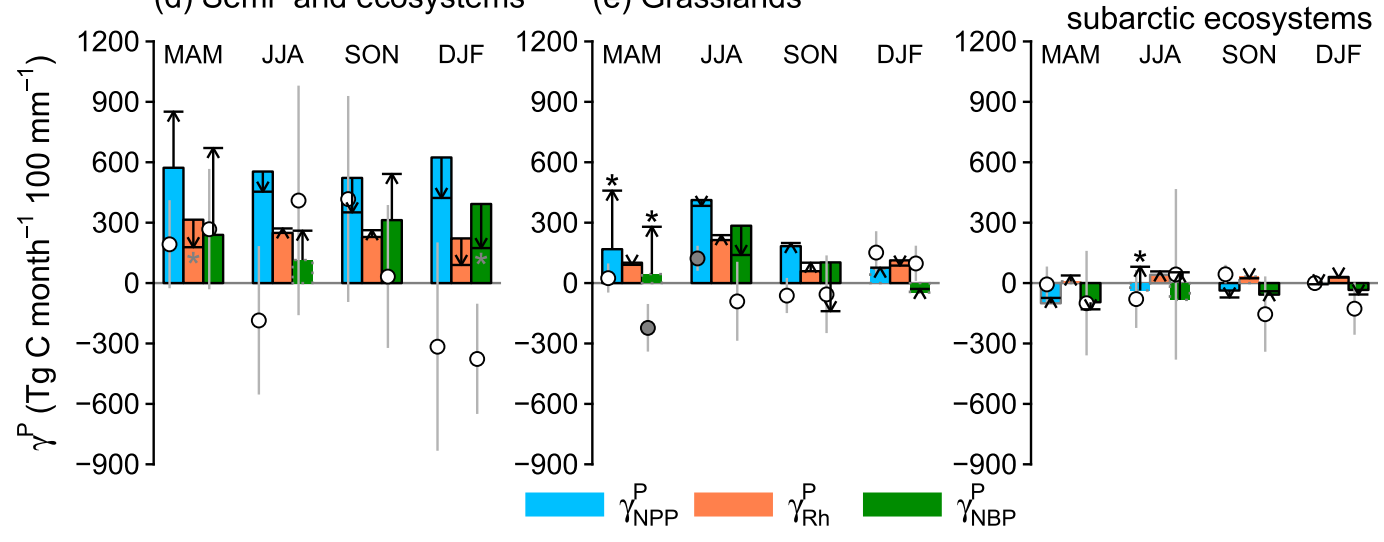

FIG. 6. Multimodel median seasonal $\gamma_{\mathrm{NPP}}^{P}, \gamma_{\mathrm{Rh}}^{P}$, and $\gamma_{\mathrm{NBP}}^{P}$ across vegetation types in the period 1982-2005 and their changes from 1982 to 2099 under RCP4.5. The dots represent observation derived $\gamma^{P}$ in the period 1982-2005. The black, gray, and white dots indicate that $\gamma^{P}$ is significant (at the 5\% level), marginally significant (at the $10 \%$ level), and nonsignificant, respectively. The gray vertical lines across the dots indicate the standard error of observation derived $\gamma^{P}$. The bars mean the $\gamma^{P}$ in the period 1982-2005. The bars with black solid, gray solid, and gray dashed borders mean that the multimodel median $\gamma^{P}$ is significant (at the $5 \%$ level), marginally significant (at the $10 \%$ level), and nonsignificant using a Wilcoxon signed-rank test, respectively. The arrows mean the changes in multimodel median seasonal $\gamma^{P}$ from 1982 to $2099\left(\Delta \gamma^{P}\right)$ under RCP4.5. The black and gray stars mean that multimodel median $\Delta \gamma^{P}$ is significant (at the $5 \%$ level) and marginally significant (at the $10 \%$ level) using a Wilcoxon signed-rank test, respectively.

precipitation variations in grasslands at global scale (Yang et al. 2008), indicating that NPP responses to $P$ vary with biomes or across spatial scales. In this study, satellite-derived $\gamma_{\mathrm{NPP}}^{P}$ across global grasslands is also marginally significant in JJA with value of $123.1 \pm$ $62.2 \mathrm{TgCmonth}^{-1}(100 \mathrm{~mm})^{-1}(p=0.062)$, but is nonsignificant in MAM and SON. Different from general nonsignificant satellite-derived $\gamma_{\mathrm{NPP}}^{P}, \gamma_{\mathrm{NPP}}^{P}$ in ESMs, however, are generally positive (Figs. 6 and 7b-r). This indicates that in current ESMs, vegetation growth is too sensitive to precipitation variations compared to satellitederived estimations.

By the end of the twenty-first century, projected $\gamma_{\mathrm{NPP}}^{P}$ generally does not change under RCP4.5 compared to present day across all biomes, except for temperate forests in JJA and grasslands in MAM with multimodel median $\Delta \gamma_{\mathrm{NPP}}^{P}$ of $57.6_{13.5}^{136.5} \pm 4.1(p=0.017)$ and
$249.6_{-48.3}^{520.3} \pm 107.4 \mathrm{TgC} \mathrm{month}^{-1}(100 \mathrm{~mm})^{-1}(p=0.039)$, respectively (Fig. 6). As shown in Fig. 10, there is no clear spatial pattern of $\Delta \gamma_{\mathrm{NPP}}^{P}, \Delta \gamma_{\mathrm{Rh}}^{P}$, and $\Delta \gamma_{\mathrm{NBP}}^{P}$ in ESMs under RCP4.5. In ESMs, the photosynthetic rate usually changes linearly with changes in VPD or relative humidity (Shao et al. 2013b). Thus, the sensitivity of photosynthesis to $P$ does not changes over the twenty-first century in ESMs. There is also linear correlation between Rh and $P$ in ESMs (Shao et al. 2013a), resulting in unchanging $\gamma_{\mathrm{Rh}}^{P}$ across all biomes in ESMs (Fig. 6). Both changes in $\gamma_{\mathrm{NPP}}^{P}$ and $\gamma_{\mathrm{Rh}}^{P}$ jointly determine the changes in $\gamma_{\mathrm{NBP}}^{P}$ over the twenty-first century in ESMs. Similar to $\gamma_{\mathrm{NPP}}^{P}$, projected $\gamma_{\mathrm{NBP}}^{P}$ also generally remains unchanged under RCP4.5 across all biomes, except for grasslands in MAM with a positive multimodel median $\Delta \gamma_{\mathrm{NBP}}^{P}$ of $230.9_{134.5}^{431.0} \pm 106.2 \mathrm{TgC} \mathrm{month}^{-1}(100 \mathrm{~mm})^{-1}(p=0.003)$. This is probably because that spring vegetation phenology 
(a) Observation

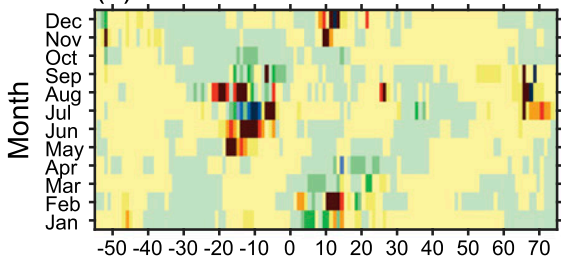

(d) CCSM4

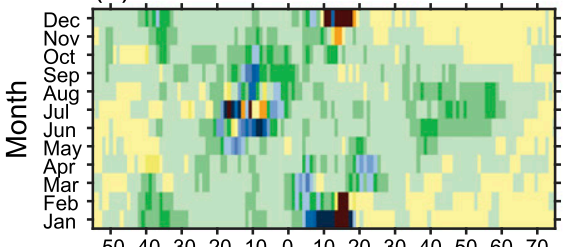

(g) GFDL-ESM2M

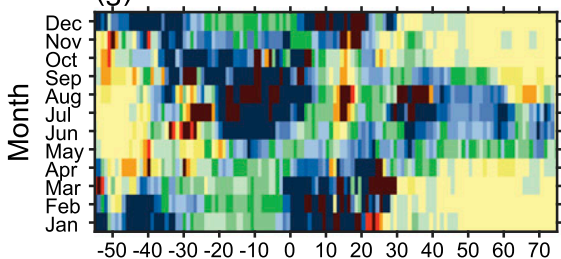

(j) IPSL-CM5A-LR

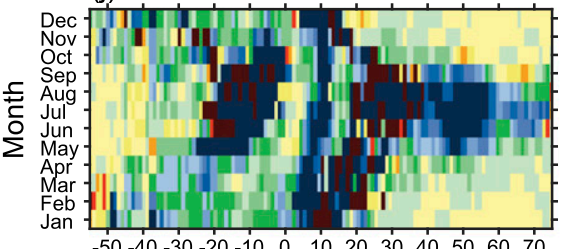

(m) MIROC-ESM-CHEM

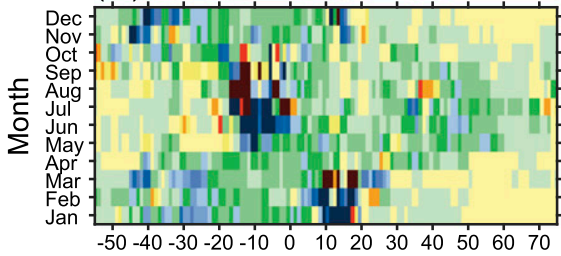

(p) MRI-ESM1

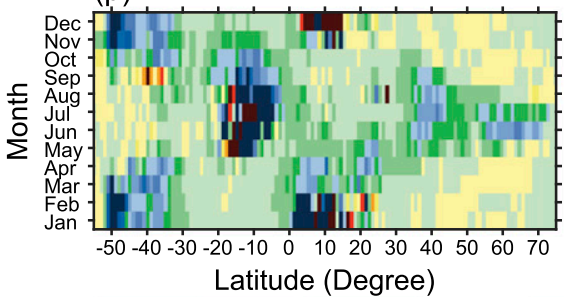

(b) BNU-ESM

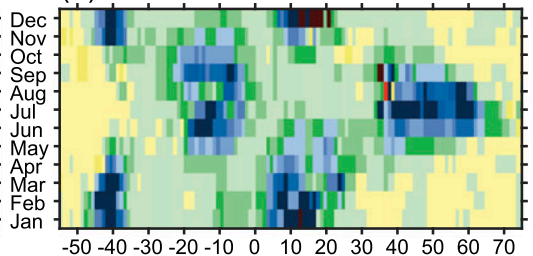

(e) CESM1-BGC

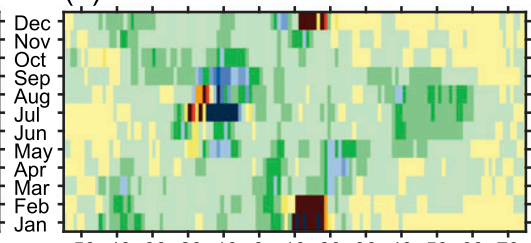

(h) HadGEM2-CC

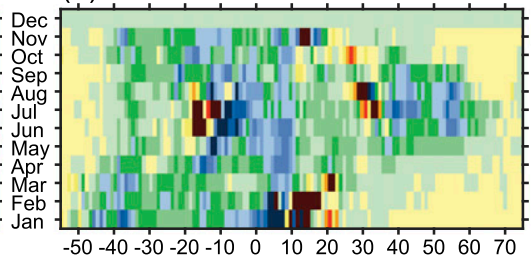

(k) IPSL-CM5B-LR

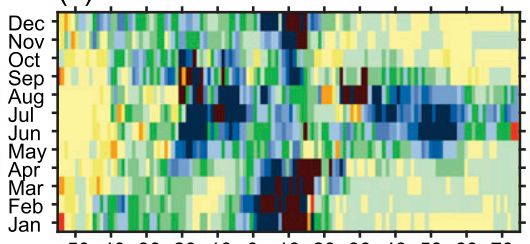

(n) MPI-ESM-LR

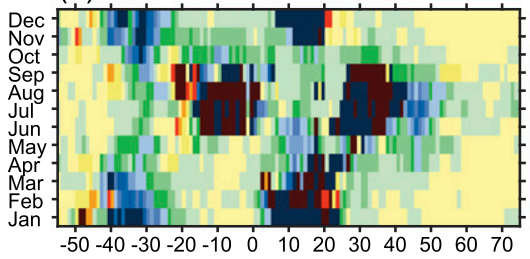

(q) NorESM1-M

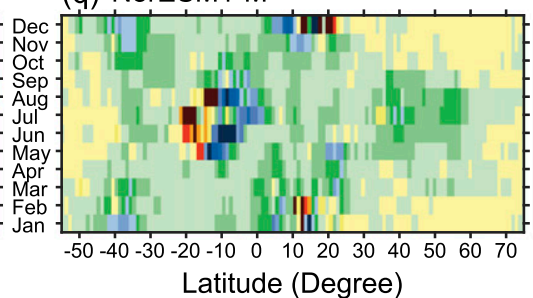

(c) CanESM2

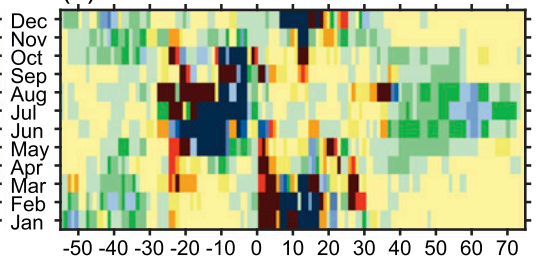

(f) GFDL-ESM2G

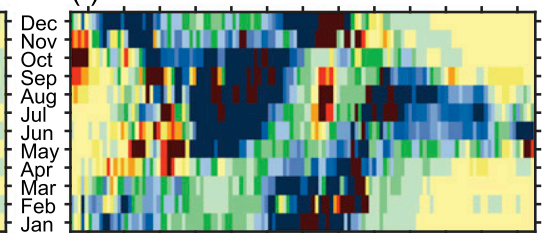

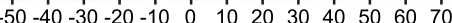

(i) HadGEM2-ES

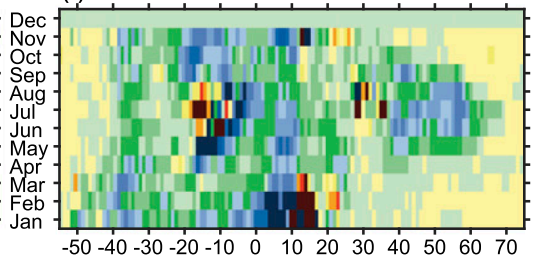

(I) MIROC-ESM

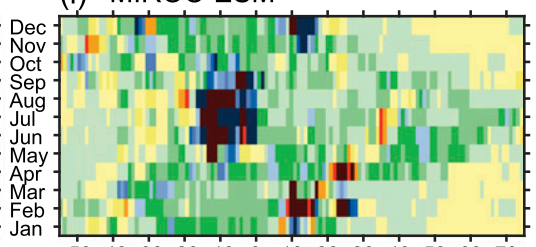

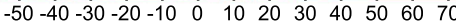

(o) MPI-ESM-MR

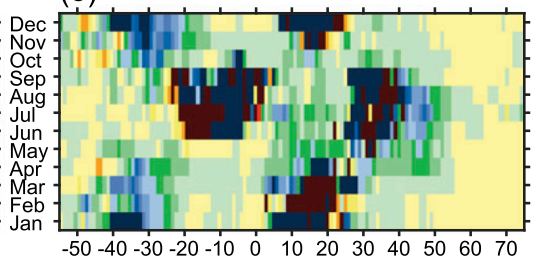

(r) NorESM1-ME

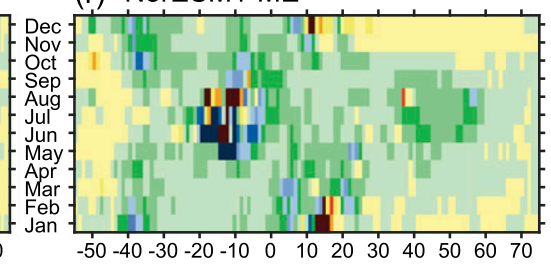
Latitude (Degree)

$$
\begin{aligned}
& -20 \\
& -15 \\
& -10 \\
& -5 \\
& 0 \\
& 5 \\
& 10 \\
& 15 \\
& 20 \\
& \gamma_{\mathrm{NPP}}^{\mathrm{P}} \text { in the period 1982-2005 }\left(\mathrm{g} \mathrm{C} \mathrm{m}^{-2} \text { month }^{-1} 100 \mathrm{~mm}^{-1}\right)
\end{aligned}
$$

FIG. 7. Spatial distributions of observed and simulated monthly $\gamma_{\mathrm{NPP}}^{P}$ in the period 1982-2005; $\gamma_{\mathrm{NPP}}^{P}$ is estimated using Eq. (1). 
(a) BNU-ESM

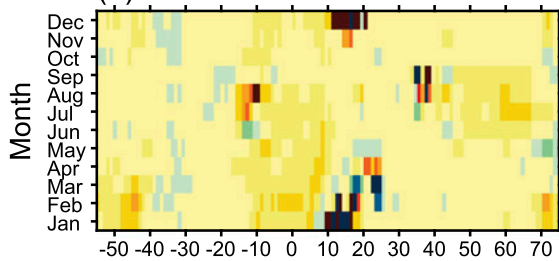

(d) CESM1-BGC

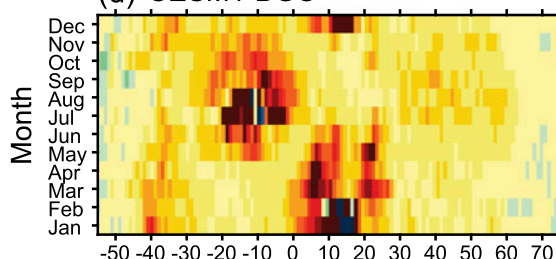

(g) HadGEM2-CC

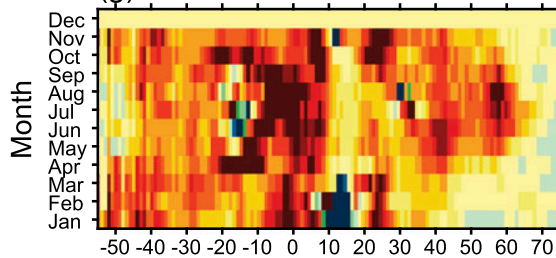

(j) IPSL-CM5B-LR

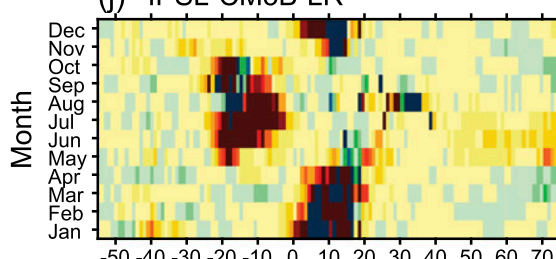

(m) MPI-ESM-LR

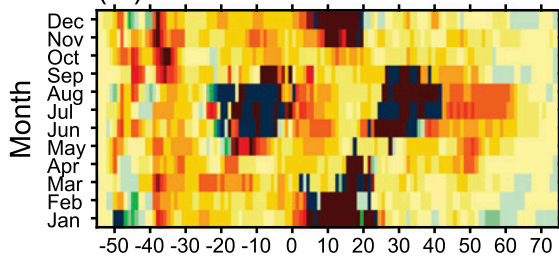

(p) NorESM1-M

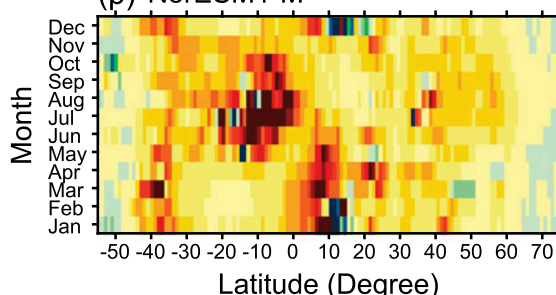

(b) CanESM2

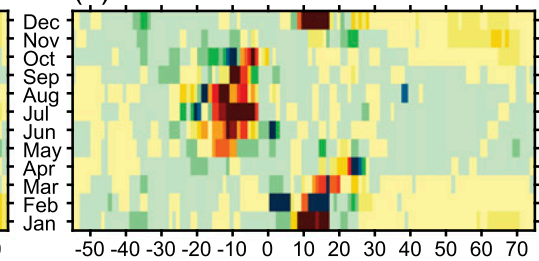

(e) GFDL-ESM2G

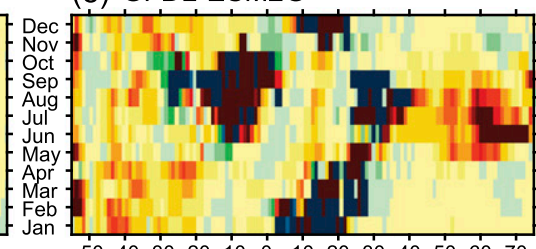

$-50-40-30-20-10 \quad 0 \quad 102030 \quad 4050 \quad 60 \quad 70$ (h) HadGEM2-ES

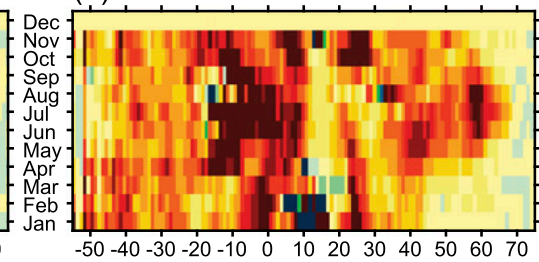

(k) MIROC-ESM

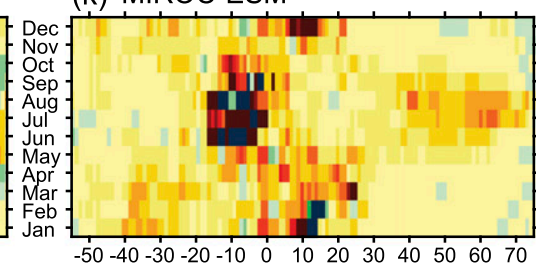

(n) MPI-ESM-MR

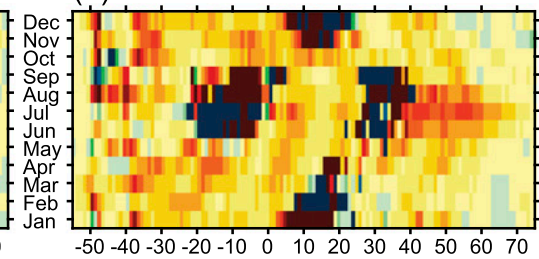

(q) NorESM1-ME (c) CCSM4

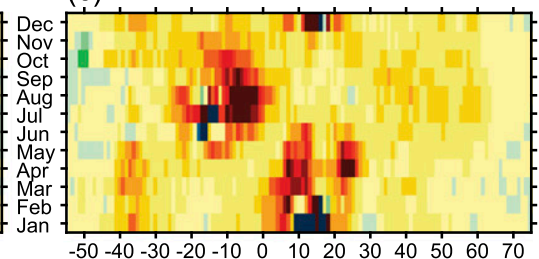

(f) GFDL-ESM2M

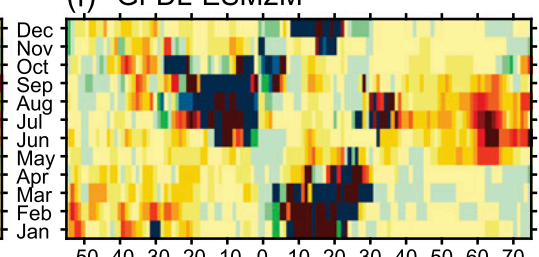

(i) IPSL-CM5A-LR

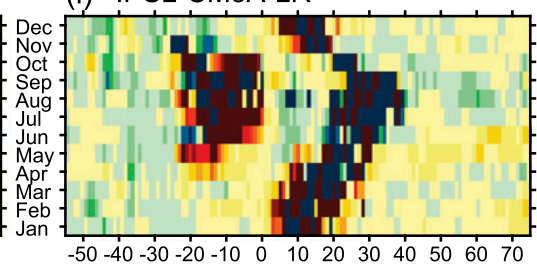

(I) MIROC-ESM-CHEM

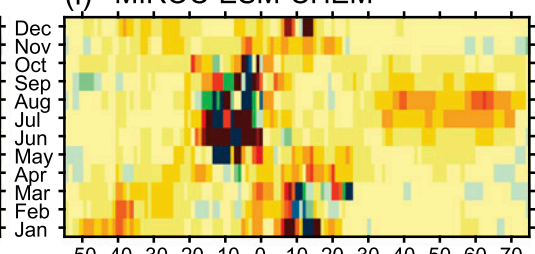

(o) MRI-ESM1

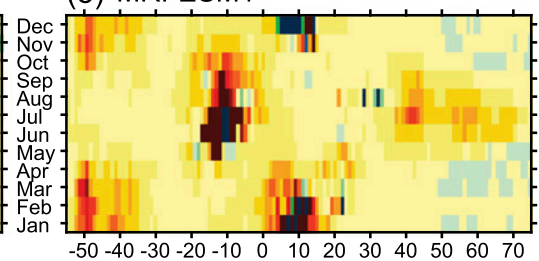

Latitude (Degree)

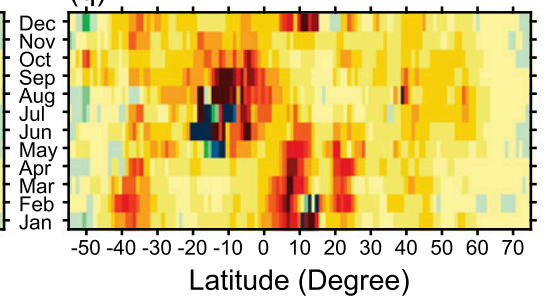

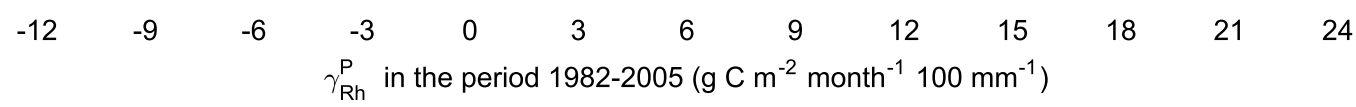

FIG. 8. Spatial distributions of simulated monthly $\gamma_{\mathrm{Rh}}^{P}$ in the period 1982-2005; $\gamma_{\mathrm{Rh}}^{P}$ is estimated using Eq. (1). 
(a) Observation

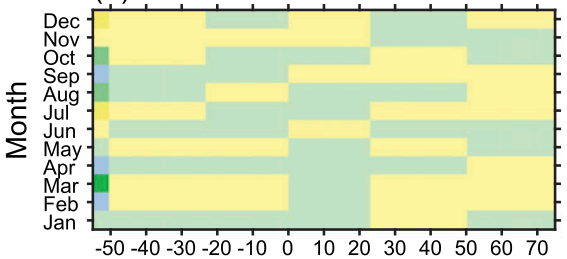

(d) CCSM4

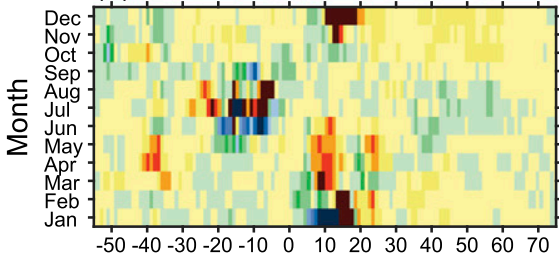

(g) GFDL-ESM2M

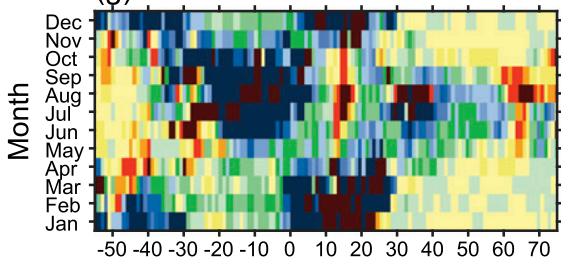

(j) IPSL-CM5A-LR

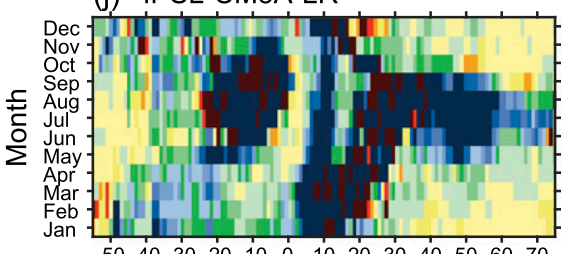

(m) MIROC-ESM-CHEM

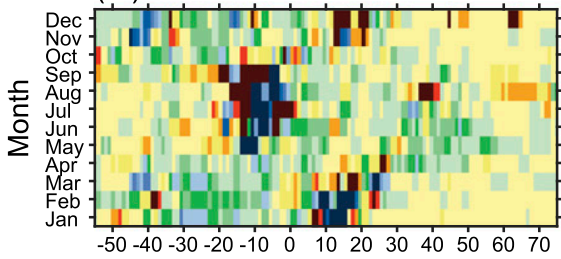

(p) MRI-ESM1

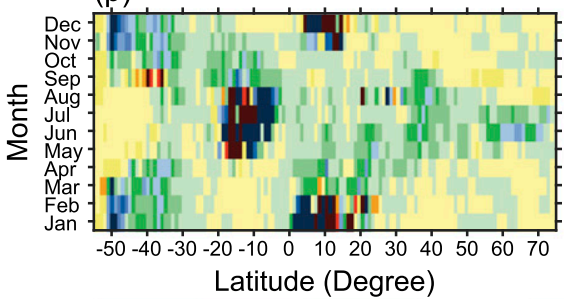

(b) BNU-ESM

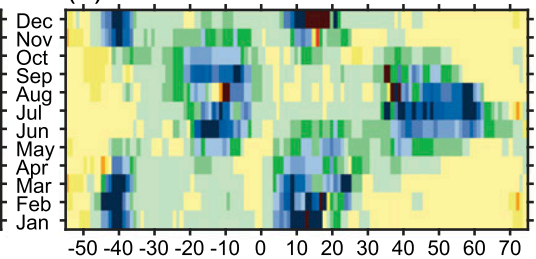

(e) CESM1-BGC

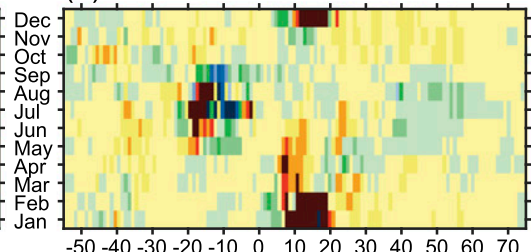

(h) HadGEM2-CC

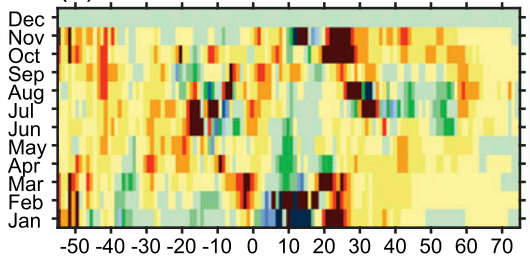

(k) IPSL-CM5B-LR

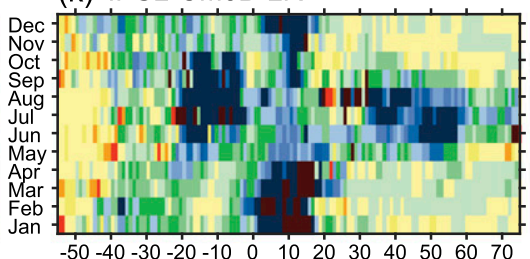

(n) MPI-ESM-LR

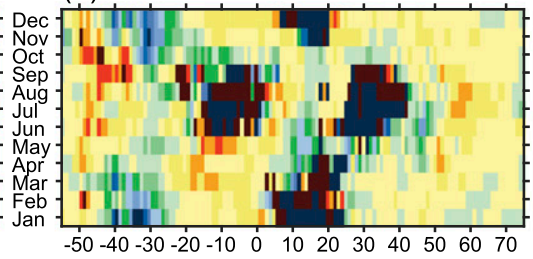

(q) NorESM1-M

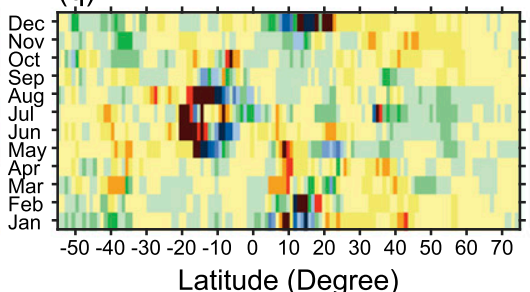

(c) CanESM2

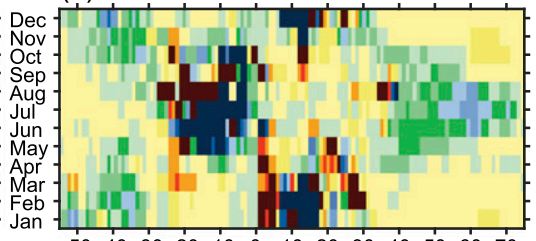

$-50-40-30-20-1000102030 \quad 40 \quad 50 \quad 60 \quad 70$

(f) GFDL-ESM2G

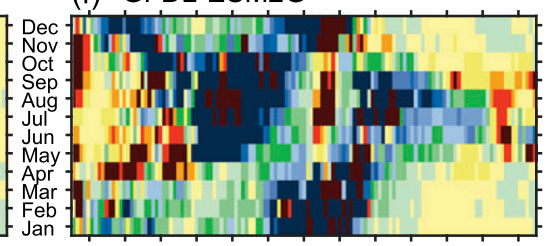

$-50-40-30-20-10 \quad 0 \quad 1020 \quad 3040 \quad 5060 \quad 70$

(i) HadGEM2-ES

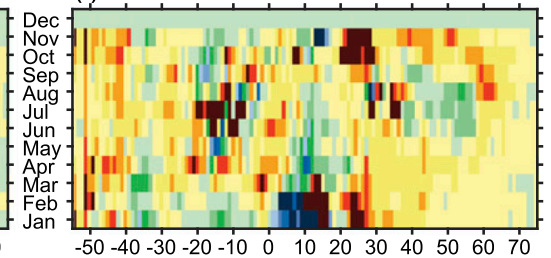

(I) MIROC-ESM

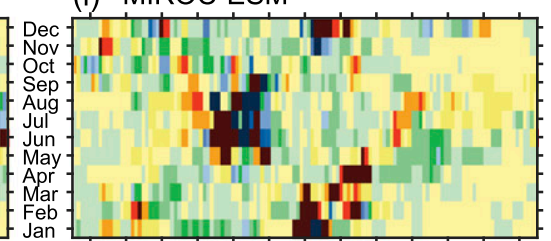

$-50-40-30-20-10 \quad 0 \quad 1020 \quad 3040 \quad 5060 \quad 70$

(o) MPI-ESM-MR

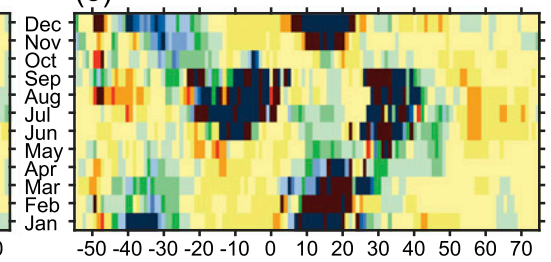

(r) NorESM1-ME

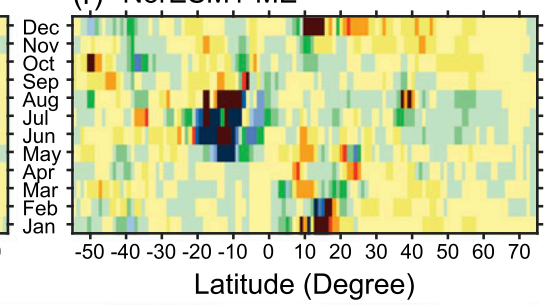

$-20$

$-15$

$-5$

0

5

10

15

20

25

30

35

40

$\gamma_{\text {NBP }}^{\mathrm{P}}$ in the period 1982-2005 $\left(\mathrm{g} \mathrm{C} \mathrm{m}^{-2}\right.$ month $\left.^{-1} 100 \mathrm{~mm}^{-1}\right)$

FIG. 9. Spatial distributions of observed and simulated monthly $\gamma_{\mathrm{NBP}}^{P}$ in the period 1982-2005; $\gamma_{\mathrm{NBP}}^{P}$ is estimated using Eq. (1). 
(a)

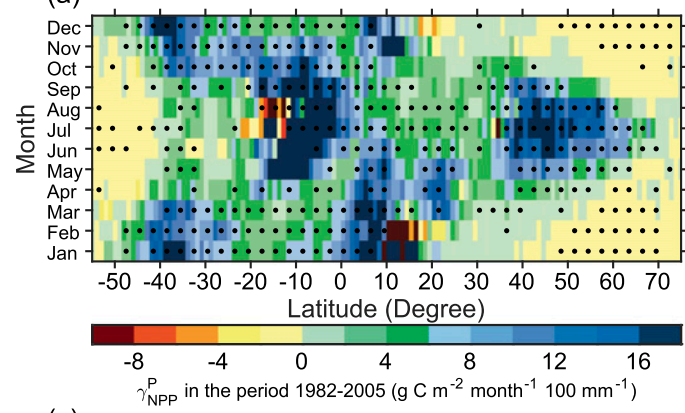

(c)

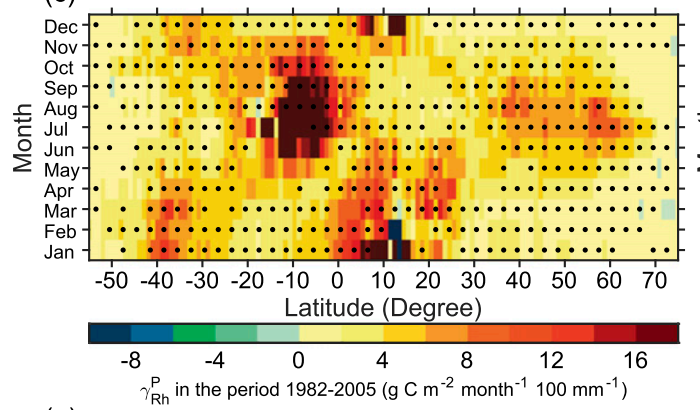

(e)

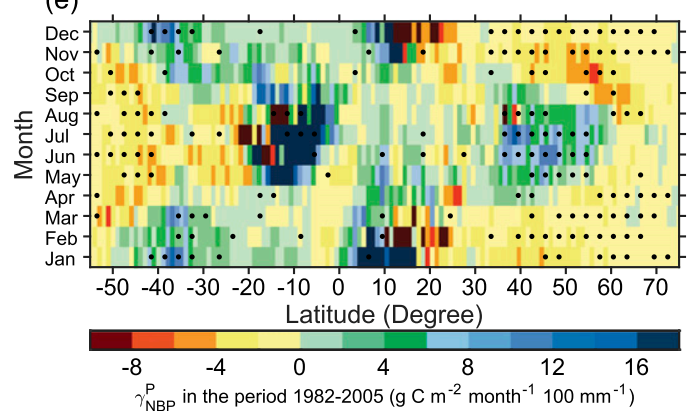

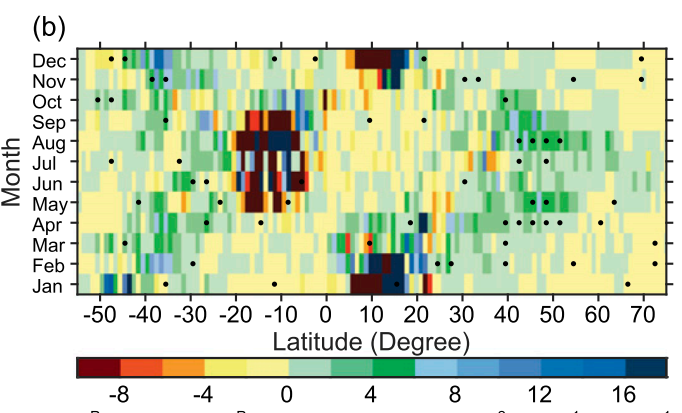

(d)

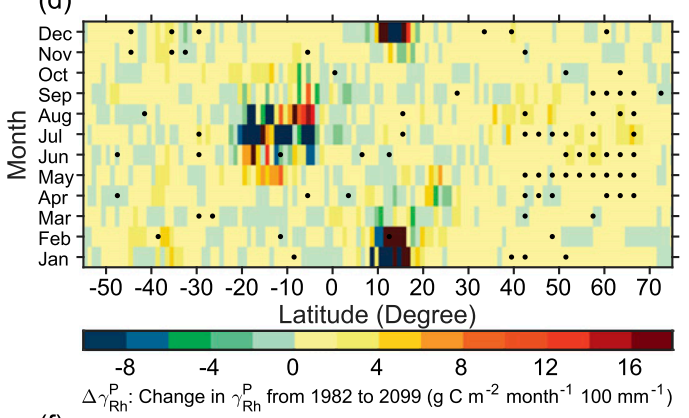

(f)

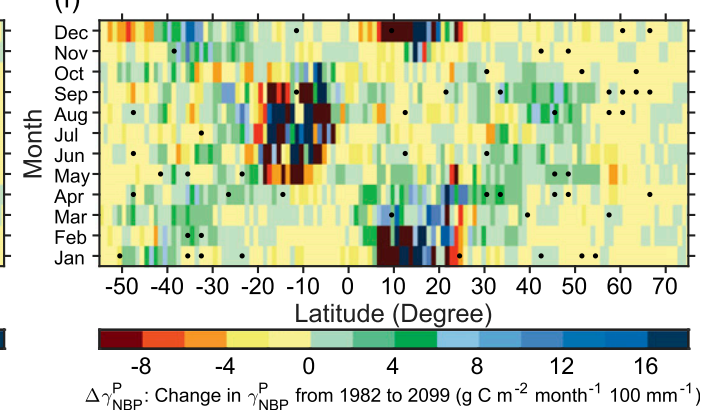

FIG. 10. Spatial distributions of multimodel median (a) $\gamma_{\mathrm{NPP}}^{P}$, (c) $\gamma_{\mathrm{Rh}}^{P}$, and (e) $\gamma_{\mathrm{NBP}}^{P}$, and (b), (d), (f) their respective changes from 1982 to 2099 under RCP4.5. Values of $\gamma_{\mathrm{NPP}}^{P}, \gamma_{\mathrm{Rh}}^{P}$, and $\gamma_{\mathrm{NBP}}^{P}$ are estimated using Eq. (1); $\Delta \gamma_{\mathrm{NPP}}^{P}, \Delta \gamma_{\mathrm{Rh}}^{P}$, and $\Delta \gamma_{\mathrm{NBP}}^{P}$ are calculated as the difference of $\gamma_{\mathrm{NPP}}^{P}, \gamma_{\mathrm{Rh}}^{P}$, and $\gamma_{\mathrm{NBP}}^{P}$, respectively, between the periods 2076-99 (RCP4.5 runs) and 1982-2005 (historical simulations). Black dots indicate significance at the 5\% level using a Wilcoxon signed-rank test. Models used are BNU-ESM, CanESM2, CCSM4, CESM1(BGC), GFDL-ESM2M, GFDL-ESM2G, HadGEM2-CC, HadGEM2-ES, IPSL-CM5A-LR, IPSL-CM5B-LR, MIROC-ESM, MIROCESM-CHEM, MPI-ESM-LR, MPI-ESM-MR, NorESM1-M, and NorESM1-ME.

in grasslands is closely related with precipitation in models (Hufkens et al. 2016). Projected increases in growing season length due to both warming and increasing precipitation, will partly contribute to the increase in $\gamma_{\mathrm{NPP}}^{P}$ and $\gamma_{\mathrm{NBP}}^{P}$ in grasslands over the twenty-first century under RCP4.5. Note that $\Delta \gamma_{\mathrm{NPP}}^{P}, \Delta \gamma_{\mathrm{Rh}}^{P}$, and $\Delta \gamma_{\mathrm{NBP}}^{P}$ are generally consistent across RCP2.6, RCP4.5, RCP6.0, and RCP8.5 (Figs. S14-S23 in the supplemental material).

\section{c. Interannual radiation sensitivities of seasonal carbon fluxes}

Figures S24-S39 in the supplemental material show the seasonal sensitivities of carbon fluxes (NPP, Rh, and NBP) to $R$ in ESMs during 1982-2005 and their changes over the twenty-first century under RCP2.6, RCP4.5, RCP6.0, and RCP8.5. In most ESMs, NPP is positively related with $R$ in tropics, and NH middle and high latitudes in NH summer (Fig. S29). However, there is no apparent correlation between $\mathrm{Rh}$ and $R$ globally (Fig. S30). The $\gamma_{\mathrm{NBP}}^{R}$ Over the past three decades is generally dominated by $\gamma_{\mathrm{NPP}}^{R}$, rather than $\gamma_{\mathrm{Rh}}^{R}$ across global terrestrial ecosystem in ESMs (Fig. S31). By the end of twenty-first century, the changes in $\gamma_{\mathrm{NPP}}^{R}$ has large spatial heterogeneity in ESMs under all RCPs (Figs. S36-S39). Overall, $\gamma_{\mathrm{NBP}}^{R}$ increases in boreal forests and subarctic ecosystems under RCP8.5, but does not show apparent change in the other biomes under all RCPs (Fig. S28). 
Finally, we separated the direct effect of $T$ and $P$ on $\mathrm{NPP}\left(\gamma_{\mathrm{NPP}}^{T M}\right.$ and $\left.\gamma_{\mathrm{NPP}}^{P}\right)$ by controlling the soil moisture in the multiple regression approach in Eq. (2). Results show that $\gamma_{\mathrm{NPP}}^{T}$ and $\gamma_{\mathrm{NPP}}^{T}-M$ are significant correlated across models in all biomes at all season (Fig. S40 in the supplemental material). The ratio between the multimodel median of $\gamma_{\mathrm{NPP}}^{T-M}$ and the multimodel median of $\gamma_{\mathrm{NPP}}^{T}$ is larger than $50 \%$ in all biomes at all season. This indicates that the temperature variation mainly directly influence NPP, rather than indirectly affect NPP via changing soil moisture. Nonetheless, the indirect effect of temperature on NPP cannot be ignored in tropical forests, semiarid ecosystems, and grasslands, particular in MAM and JJA. Probably because of these indirect effects, there are time-lag effects in vegetation growth responses to climate change in reality (Wu et al. 2015), which are recommended to be considered in the understanding terrestrial carbon cycle dynamics under climate change in future work. Different from significant $\gamma_{\mathrm{NPP}}^{T-M}$, NPP is decoupled from $P$ in most models when soil moisture is controlled with insignificant $\gamma_{\mathrm{NPP}}^{P}$, particular in tropical forests (Fig. S41 in the supplemental material). This indicates that the effect of $P$ on NPP is mainly through changing soil moisture.

\section{Summary}

The responses of terrestrial carbon fluxes to interannual climate variations are season-specific and change with time. However, season-specific climate sensitivities of the terrestrial carbon cycle and their changes over time due to future climate change remain largely unknown. In this paper, we evaluated CMIP5 ESMs for their seasonal interannual sensitivities of net primary production (NPP) and net biome production (NBP) sensitivities to variations of temperature $T$ and precipitation $P$ during 1982-2005 $\left(\gamma^{T}\right.$ and $\gamma^{P}$, respectively) for different biomes (tropical forests, temperate forests, boreal forests, semiarid ecosystems, grasslands, and shrublands and subarctic ecosystems). ESM interannual sensitivities were compared with satellite-derived NPP and inversion-based NBP datasets. We further investigated the changes in seasonal sensitivities of NPP, heterotrophic respiration $(\mathrm{Rh})$, and NBP to $T$ and $P$ over the twenty-first century $\left(\Delta \gamma^{T}\right.$ and $\Delta \gamma^{P}$, respectively) under RCP2.6, RCP4.5, RCP6.0, and RCP8.5 in CMIP5 ESMs. We summarize here the main findings.

1) Compared with satellite-derived $\gamma_{\mathrm{NPP}}^{T}$ in most seasons, ESMs generally capture the positive $\gamma_{\mathrm{NPP}}^{T}$ in $\mathrm{NH}$ high latitudes (e.g., boreal forests, and shrublands and subarctic ecosystems), but ESMs give stronger than observed negative $\gamma_{\mathrm{NPP}}^{T}$ across the tropics and subtropics (e.g., tropical forests and semiarid ecosystems). Satellite-derived NPP is suitable for assessing the $\gamma_{\mathrm{NPP}}^{T}$ in boreal forests and subarctic ecosystems, while in the tropics, the uncertainties of satellite-derived NPP, especially interannual variability, are large. The calculation of satellite-derived NPP is influenced by FPAR though a light-use efficiency model and LAI, both of which, however, can saturate in the tropical forests Smith et al. (2016). Moreover, usable optical satellite images in tropical regions are limited, because of persistent cloud cover especially during the rainy season, posing a significant challenge to interannual analysis (Reiche et al. 2016). Compared with the regional-scale evaluation, the $\gamma_{\mathrm{NPP}}^{T}$ in tropical ecosystems from ESMs may be more accurately accessed using long term NPP observations at site scale.

2) The responses of inversion-based NBP to $T$ is significant in boreal forests, tropical forests, and semiarid ecosystems, but not in other biomes. In boreal forests, ESMs generally capture the positive $\gamma_{\mathrm{NBP}}^{T}$ in MAM and SON, but underestimate the strength of negative responses of NBP to $T$ in summer (JJA). In tropical forests and semiarid ecosystems, $\gamma_{\mathrm{NBP}}^{T}$ across ESMs is negative in all seasons, while inversion-based $\gamma_{\mathrm{NBP}}^{T}$ is negative only in MAM and SON and is nonsignificant in JJA. This is probably because the $\mathrm{CO}_{2}$ measurement stations are mainly distributed in the $\mathrm{NH}$ middle and high latitudes, and tropical oceans but rare on tropical lands (Chevallier et al. 2010). For the biomes with relative lower productivity (e.g., grasslands), the inversionbased $\gamma_{\mathrm{NBP}}^{T}$ might be overestimated. Thus, to better understand and evaluate $\gamma_{\mathrm{NBP}}^{T}$ in tropical ecosystems and grasslands, more accurate estimation of responses of seasonal NBP to $T$ in these regions remains to be detected via in situ observations, such as, flux tower measurements, and manipulative warming experiments (Cavaleri et al. 2015) at whole-ecosystem scales (Fayle et al. 2015).

3) Over the twenty-first century, changes in $\gamma_{\mathrm{NPP}}^{T}, \gamma_{\mathrm{Rh}}^{T}$, and $\gamma_{\mathrm{NBP}}^{T}$ are consistent across RCP2.6, RCP4.5, RCP6.0, and RCP8.5 but are larger in magnitude under more intensive scenarios. Generally, projected $\gamma_{\mathrm{NBP}}^{T}$ in MAM become more negative in tropical forests and semiarid ecosystems, but become more positive in boreal forests, and shurblands and subarctic ecosystems. While projected $\gamma_{\mathrm{NBP}}^{T}$ in JJA and SON declines across all biomes. Particularly in NH high latitudes (e.g., boreal forests), the stronger negative $\gamma_{\mathrm{NBP}}^{T}$ is due to both a decrease in negative $\gamma_{\mathrm{NPP}}^{T}$ and an increase in positive $\gamma_{\mathrm{Rh}}^{T}$. However, it is noteworthy that terrestrial ecosystems 
in the northern high latitudes contain huge organic carbon stock, which is sensitive to climate change (Koven et al. 2015; Schuur et al. 2015). Permafrost carbon dynamics is not explicitly represented in current ESMs for deep permafrost carbon (Luo et al. 2016), leading to large uncertainty in the projected changes in soil organic carbon over the twenty-first century (Todd-Brown et al. 2014). Thus, to more accurately understand the seasonal dynamic processes of terrestrial carbon cycle, it is essential to project soil carbon dynamics more realistically in ESMs in the future work.

In short, accurate understanding and representing the relationship between carbon fluxes and climate in ESMs is essential for fundamentally improving predictive responses and feedbacks of terrestrial ecosystems cycle to future climate change. In addition to considering mean annual variations in climate (Y. Liu et al. 2016), the carbon-climate correlation is recommended to be concerned separately for each season since climate variations (e.g., $T$ and $P$ ) are known to exert different controls on seasonal $\mathrm{CO}_{2}$ fluxes. To better evaluate the performance of ESMs at regional or global scales, the quality of observation-based $\mathrm{CO}_{2}$ fluxes datasets remains to be improved, particular in tropical and subtropical zones. To better represent the carbon-climate interaction in ESMs, realistic responses of carbon fluxes to climate change are recommended to be investigated particular in tropics and northern permafrost regions using in situ perturbation experiments, such as manipulative warming experiments.

Acknowledgments. This study was supported by the National Natural Science Foundation of China (41530528 and 41561134016), the 111 Project, and the National Youth Top-notch Talent Support Program in China. P.C. acknowledges support from the European Research Council Synergy Grant ERC-2013-SyG610028 IMBALANCE-P. We acknowledge Chris Jones and the other two anonymous reviewers for their constructive and helpful comments that greatly improved the quality of this paper.

\section{REFERENCES}

Ahlström, A., G. Schurgers, A. Arneth, and B. Smith, 2012: Robustness and uncertainty in terrestrial ecosystem carbon response to CMIP5 climate change projections. Environ. Res. Lett., 7, 044008, doi:10.1088/1748-9326/7/4/044008.

Angert, A., S. Biraud, C. Bonfils, C. C. Henning, W. Buermann, J. Pinzon, C. J. Tucker, and I. Fung, 2005: Drier summers cancel out the $\mathrm{CO}_{2}$ uptake enhancement induced by warmer springs. Proc. Natl. Acad. Sci. USA, 102, 10823-10827, doi:10.1073/pnas.0501647102.
Babst, F., and Coauthors, 2013: Site- and species-specific responses of forest growth to climate across the European continent. Global Ecol. Biogeogr., 22, 706-717, doi:10.1111/ geb.12023.

Barichivich, J., K. R. Briffa, R. Myneni, G. Schrier, W. Dorigo, C. J. Tucker, T. J. Osborn, and T. M. Melvin, 2014: Temperature and snow-mediated moisture controls of summer photosynthetic activity in northern terrestrial ecosystems between 1982 and 2011. Remote Sens., 6, 1390-1431, doi:10.3390/rs6021390.

Cavaleri, M. A., S. C. Reed, W. K. Smith, and T. E. Wood, 2015: Urgent need for warming experiments in tropical forests. Global Change Biol., 21, 2111-2121, doi:10.1111/gcb.12860.

Chevallier, F., and Coauthors, 2005: Inferring $\mathrm{CO}_{2}$ sources and sinks from satellite observations: Method and application to TOVS data. J. Geophys. Res., 110, D24309, doi:10.1029/ 2005JD006390.

— , and Coauthors, 2010: $\mathrm{CO}_{2}$ surface fluxes at grid point scale estimated from a global 21 year reanalysis of atmospheric measurements. J. Geophys. Res., 115, D21307, doi:10.1029/ 2010JD013887.

—, P. I. Palmer, L. Feng, H. Boesch, C. W. O'Dell, and P. Bousquet, 2014: Toward robust and consistent regional $\mathrm{CO}_{2}$ flux estimates from in situ and spaceborne measurements of atmospheric $\mathrm{CO}_{2}$. Geophys. Res. Lett., 41, 1065-1070, doi:10.1002/2013GL058772.

Cinquini, L., and Coauthors, 2014: The Earth System Grid Federation: An open infrastructure for access to distributed geospatial data. Future Gener. Comput. Syst., 36, 400-417, doi:10.1016/j.future.2013.07.002.

Collins, M., and Coauthors, 2013: Long-term climate change: Projections, commitments and irreversibility. Climate Change 2013: The Physical Science Basis, T. F. Stocker, et al., Eds., Cambridge University Press, 1029-1136, doi:10.1017/ CBO9781107415324.024.

Corlett, R. T., 2011: Impacts of warming on tropical lowland rainforests. Trends Ecol. Evol., 26, 606-613, doi:10.1016/ j.tree.2011.06.015.

Curry, C. L., and Coauthors, 2014: A multimodel examination of climate extremes in an idealized geoengineering experiment. J. Geophys. Res. Atmos., 119, 3900-3923, doi:10.1002/ 2013JD020648.

Dai, A. G., 2013: Increasing drought under global warming in observations and models. Nat. Climate Change, 3, 52-58, doi: $10.1038 /$ nclimate 1633 .

Donat, M. G., J. Sillmann, S. Wild, L. V. Alexander, T. Lippmann, and F. W. Zwiers, 2014: Consistency of temperature and precipitation extremes across various global gridded in situ and reanalysis datasets. J. Climate, 27, 5019-5035, doi:10.1175/ JCLI-D-13-00405.1.

Doughty, C. E., and M. L. Goulden, 2008: Are tropical forests near a high temperature threshold? J. Geophys. Res., 113, G00B07, doi:10.1029/2007jg000632.

Dragoni, D., H. P. Schmid, C. A. Wayson, H. Potter, C. S. B. Grimmond, and J. C. Randolph, 2011: Evidence of increased net ecosystem productivity associated with a longer vegetated season in a deciduous forest in south-central Indiana, USA. Global Change Biol., 17, 886-897, doi:10.1111/ j.1365-2486.2010.02281.x.

Dwyer, J. G., M. Biasutti, and A. H. Sobel, 2012: Projected changes in the seasonal cycle of surface temperature. J. Climate, $\mathbf{2 5}$, 6359-6374, doi:10.1175/JCLI-D-11-00741.1.

Elmendorf, S. C., and Coauthors, 2012: Plot-scale evidence of tundra vegetation change and links to recent summer 
warming. Nat. Climate Change, 2, 453-457, doi:10.1038/ nclimate1465.

Fatichi, S., V. Y. Ivanov, and E. Caporali, 2012: Investigating interannual variability of precipitation at the global scale: Is there a connection with seasonality? J. Climate, 25, 5512-5523, doi:10.1175/JCLI-D-11-00356.1.

Fayle, T. M., E. C. Turner, Y. Basset, R. M. Ewers, G. Reynolds, and V. Novotny, 2015: Whole-ecosystem experimental manipulations of tropical forests. Trends Ecol. Evol., 30, 334-346, doi:10.1016/j.tree.2015.03.010.

Feng, S., and Q. Fu, 2013: Expansion of global drylands under a warming climate. Atmos. Chem. Phys., 13, 10 081-10094, doi:10.5194/acp-13-10081-2013.

Forkel, M., N. Carvalhais, C. Rödenbeck, R. Keeling, M. Heimann, K. Thonicke, S. Zaehle, and M. Reichstein, 2016: Enhanced seasonal $\mathrm{CO}_{2}$ exchange caused by amplified plant productivity in northern ecosystems. Science, 351, 696-699, doi:10.1126/ science.aac4971.

Friedl, M. A., D. Sulla-Menashe, B. Tan, A. Schneider, N. Ramankutty, A. Sibley, and X. M. Huang, 2010: MODIS Collection 5 global land cover: Algorithm refinements and characterization of new datasets. Remote Sens. Environ., 114, 168-182, doi:10.1016/j.rse.2009.08.016.

Friedlingstein, P., and Coauthors, 2006: Climate-carbon cycle feedback analysis: Results from the $\mathrm{C}^{4} \mathrm{MIP}$ model intercomparison. J. Climate, 19, 3337-3353, doi:10.1175/JCLI3800.1.

Gang, C., and Coauthors, 2015: Comparative assessment of grassland NPP dynamics in response to climate change in China, North America, Europe and Australia from 1981 to 2010. J. Agron. Crop Sci., 201, 57-68, doi:10.1111/jac.12088.

Garonna, I., R. de Jong, and M. E. Schaepman, 2016: Variability and evolution of global land surface phenology over the past three decades (1982-2012). Global Change Biol., 22, 14561468, doi: $10.1111 / \mathrm{gcb} .13168$.

Graven, H. D., and Coauthors, 2013: Enhanced seasonal exchange of $\mathrm{CO}_{2}$ by northern ecosystems since 1960 . Science, $\mathbf{3 4 1}, 1085$ 1089, doi:10.1126/science.1239207.

Graversen, R. G., T. Mauritsen, M. Tjernstrom, E. Källén, and G. Svensson, 2008: Vertical structure of recent Arctic warming. Nature, 451, 53-56, doi:10.1038/nature06502.

Gremer, J. R., J. B. Bradford, S. M. Munson, and M. C. Duniway, 2015: Desert grassland responses to climate and soil moisture suggest divergent vulnerabilities across the southwestern United States. Global Change Biol., 21, 4049-4062, doi:10.1111/ gcb.13043.

Guan, K., and Coauthors, 2014: Terrestrial hydrological controls on land surface phenology of African savannas and woodlands. J. Geophys. Res. Biogeosci., 119, 1652-1669, doi:10.1002/ 2013JG002572.

Hartmann, D. L., and Coauthors, 2013: Observations: Atmosphere and surface. Climate Change 2013: The Physical Science Basis. T. F. Stocker, et al., Eds., Cambridge University Press, 159-254, doi:10.1017/CBO9781107415324.008.

Hoye, T. T., E. Post, H. Meltofte, N. M. Schmidt, and M. C Forchhammer, 2007: Rapid advancement of spring in the High Arctic. Curr. Biol., 17, R449-R451, doi:10.1016/ j.cub.2007.04.047.

Hufkens, K., and Coauthors, 2016: Productivity of North American grasslands is increased under future climate scenarios despite rising aridity. Nat. Climate Change, 6, 710-714, doi:10.1038/ nclimate2942.

Jones, P. D., and I. Harris, 2008: Climatic Research Unit (CRU) timeseries datasets of variations in climate with variations in other phenomena. NCAS British Atmospheric Data Centre, accessed 9 April 2016. [Available online at http://catalogue.ceda.ac.uk/ uuid/3f8944800cc48e1cbc29a5ee12d8542d.]

Jones, P. W., 1999: First- and second-order conservative remapping schemes for grids in spherical coordinates. Mon. Wea. Rev., 127, 2204-2210, doi:10.1175/1520-0493(1999)127<2204: FASOCR $>2.0 . \mathrm{CO} ; 2$.

Keeling, C. D., J. F. S. Chin, and T. P. Whorf, 1996: Increased activity of northern vegetation inferred from atmospheric $\mathrm{CO}_{2}$ measurements. Nature, 382, 146-149, doi:10.1038/382146a0.

Keenan, T. F., and Coauthors, 2014: Net carbon uptake has increased through warming-induced changes in temperate forest phenology. Nat. Climate Change, 4, 598-604, doi:10.1038/ nclimate2253.

Knapp, A. K., and M. D. Smith, 2001: Variation among biomes in temporal dynamics of aboveground primary production. Science, 291, 481-484, doi:10.1126/science.291.5503.481.

Kottek, M., J. Grieser, C. Beck, B. Rudolf, and F. Rubel, 2006: World map of the Köppen-Geiger climate classification updated. Meteor. Z., 15, 259-263, doi:10.1127/ 0941-2948/2006/0130.

Koven, C. D., D. M. Lawrence, and W. J. Riley, 2015: Permafrost carbon-climate feedback is sensitive to deep soil carbon decomposability but not deep soil nitrogen dynamics. Proc. Natl. Acad. Sci. USA, 112, 3752-3757, doi:10.1073/pnas.1415123112.

Liu, Q., Y. H. Fu, Z. Zhu, Y. Liu, Z. Liu, M. Huang, I. A. Janssens, and S. Piao, 2016: Delayed autumn phenology in the Northern Hemisphere is related to change in both climate and spring phenology. Global Change Biol., 22, 3702-3711, doi:10.1111/ gcb.13311.

Liu, Y., T. Wang, M. Huang, Y. Yao, P. Ciais, and S. Piao, 2016: Changes in interannual climate sensitivities of terrestrial carbon fluxes during the 21st century predicted by CMIP5 Earth system models. J. Geophys. Res. Biogeosci., 121, 903-918, doi:10.1002/2015JG003124.

Luo, Y., and Coauthors, 2016: Toward more realistic projections of soil carbon dynamics by Earth system models. Global Biogeochem. Cycles, 30, 40-56, doi:10.1002/2015GB005239.

Lynch, C., A. Seth, and J. Thibeault, 2016: Recent and projected annual cycles of temperature and precipitation in the northeast United States from CMIP5. J. Climate, 29, 347-365, doi:10.1175/JCLI-D-14-00781.1.

Ma, X., and Coauthors, 2013: Spatial patterns and temporal dynamics in savanna vegetation phenology across the North Australian tropical transect. Remote Sens. Environ., 139, 97 115, doi:10.1016/j.rse.2013.07.030.

Ma, Z., and Coauthors, 2012: Regional drought-induced reduction in the biomass carbon sink of Canada's boreal forests. Proc. Natl. Acad. Sci. USA, 109, 2423-2427, doi:10.1073/pnas.1111576109.

Murray-Tortarolo, G., and Coauthors, 2016: The dry season intensity as a key driver of NPP trends. Geophys. Res. Lett., 43, 2632-2639, doi:10.1002/2016GL068240.

Myers-Smith, I. H., and Coauthors, 2011: Shrub expansion in tundra ecosystems: Dynamics, impacts and research priorities. Environ. Res. Lett., 6, 045509, doi:10.1088/1748-9326/6/4/ 045509.

Norby, R. J., and Coauthors, 2016: Model-data synthesis for the next generation of forest free-air $\mathrm{CO}_{2}$ enrichment (FACE) experiments. New Phytol., 209, 17-28, doi:10.1111/nph.13593.

Orlowsky, B., and S. I. Seneviratne, 2013: Elusive drought: Uncertainty in observed trends and short- and long-term CMIP5 projections. Hydrol. Earth Syst. Sci., 17, 1765-1781, doi:10.5194/hess-17-1765-2013. 
Parmesan, C., 2006: Ecological and evolutionary responses to recent climate change. Annu. Rev. Ecol. Evol. Syst., 37, 637-669, doi:10.1146/annurev.ecolsys.37.091305.110100.

Peng, C. H., and Coauthors, 2011: A drought-induced pervasive increase in tree mortality across Canada's boreal forests. Nat. Climate Change, 1, 467-471, doi:10.1038/nclimate1293.

Piao, S. L., P. Friedlingstein, P. Ciais, N. Viovy, and J. Demarty, 2007: Growing season extension and its impact on terrestrial carbon cycle in the Northern Hemisphere over the past 2 decades. Global Biogeochem. Cycles, 21, GB3018, doi:10.1029/ 2006GB002888.

— ecosystems in response to autumn warming. Nature, 451, 4952, doi: 10.1038 /nature 06444.

— , and Coauthors, 2013: Evaluation of terrestrial carbon cycle models for their response to climate variability and to $\mathrm{CO}_{2}$ trends. Global Change Biol., 19, 2117-2132, doi:10.1111/ gcb.12187.

Pinzon, J. E., and C. J. Tucker, 2014: A non-stationary 1981-2012 AVHRR NDVI ${ }_{3 \mathrm{~g}}$ time series. Remote Sens., 6, 6929-6960, doi:10.3390/rs6086929.

Randerson, J. T., M. V. Thompson, T. J. Conway, I. Y. Fung, and C. B. Field, 1997: The contribution of terrestrial sources and sinks to trends in the seasonal cycle of atmospheric carbon dioxide. Global Biogeochem. Cycles, 11, 535-560, doi:10.1029/ 97GB02268.

Reiche, J., and Coauthors, 2016: Combining satellite data for better tropical forest monitoring. Nat. Climate Change, 6, 120-122, doi:10.1038/nclimate2919.

Richardson, A. D., and Coauthors, 2010: Influence of spring and autumn phenological transitions on forest ecosystem productivity. Philos. Trans. Roy. Soc., 365B, 3227-3246, doi:10.1098/rstb.2010.0102.

Rogers, A., and Coauthors, 2017: A roadmap for improving the representation of photosynthesis in Earth system models. New Phytol., 213, 22-42, doi:10.1111/nph.14283.

Ruosteenoja, K., J. Räisänen, A. Venäläinen, and M. Kämäräinen, 2016: Projections for the duration and degree days of the thermal growing season in Europe derived from CMIP5 model output. Int. J. Climatol., 36, 3039-3055, doi:10.1002/joc.4535.

Scheff, J., and D. M. W. Frierson, 2015: Terrestrial aridity and its response to greenhouse warming across CMIP5 climate models. J. Climate, 28, 5583-5600, doi:10.1175/JCLI-D-14-00480.1.

Schuur, E. A. G., and Coauthors, 2015: Climate change and the permafrost carbon feedback. Nature, 520, 171-179, doi:10.1038/nature14338.

Shao, P., X. Zeng, D. J. P. Moore, and X. Zeng, 2013a: Soil microbial respiration from observations and Earth System Models. Environ. Res. Lett., 8, 034034, doi:10.1088/1748-9326/ 8/3/034034

- — K. Kakaguchi, R. K. Monson, and X. Zeng, 2013b: Terrestrial carbon cycle: Climate relations in eight CMIP5 Earth system models. J. Climate, 26, 8744-8764, doi:10.1175/ JCLI-D-12-00831.1.

Shen, M., S. Piao, N. Cong, G. Zhang, and I. A. Janssens, 2015: Precipitation impacts on vegetation spring phenology on the Tibetan Plateau. Global Change Biol., 21, 3647-3656, doi:10.1111/gcb.12961.

,,-- X. Chen, S. An, Y. Fu, S. Wang, N. Cong, and I. A. Janssens, 2016: Strong impacts of daily minimum temperature on the green-up date and summer greenness of the Tibetan Plateau. Global Change Biol., 22, 3057-3066, doi:10.1111/ gcb.13301.
Sillmann, J., V. V. Kharin, X. Zhang, F. W. Zwiers, and D. Bronaugh, 2013: Climate extremes indices in the CMIP5 multimodel ensemble: Part 1. Model evaluation in the present climate. J. Geophys. Res. Atmos., 118, 1716-1733, doi:10.1002/ jgrd.50203.

Smith, N. G., and J. S. Dukes, 2013: Plant respiration and photosynthesis in global-scale models: Incorporating acclimation to temperature and $\mathrm{CO}_{2}$. Global Change Biol., 19, 45-63, doi:10.1111/j.1365-2486.2012.02797.x.

Smith, W. K., and Coauthors, 2016: Large divergence of satellite and Earth system model estimates of global terrestrial $\mathrm{CO}_{2}$ fertilization. Nat. Climate Change, 6, 306-310, doi:10.1038/ nclimate2879.

Sturm, M., C. Racine, and K. Tape, 2001: Climate change: Increasing shrub abundance in the Arctic. Nature, 411, 546-547, doi:10.1038/35079180.

Tape, K., M. Sturm, and C. Racine, 2006: The evidence for shrub expansion in northern Alaska and the pan-Arctic. Global Change Biol., 12, 686-702, doi:10.1111/ j.1365-2486.2006.01128.x.

Taylor, K. E., R. J. Stouffer, and G. A. Meehl, 2012: An overview of CMIP5 and the experiment design. Bull. Amer. Meteor. Soc., 93, 485-498, doi:10.1175/BAMS-D-11-00094.1.

Todd-Brown, K. E. O., J. T. Randerson, W. M. Post, F. M. Hoffman, C. Tarnocai, E. A. G. Schuur, and S. D. Allison, 2013: Causes of variation in soil carbon simulations from CMIP5 Earth system models and comparison with observations. Biogeosciences, 10, 1717-1736, doi:10.5194/ bg-10-1717-2013.

_ predicted by Earth system models during the 21st century. Biogeosciences, 11, 2341-2356, doi:10.5194/bg-11-2341-2014.

Torres, R. R., and J. A. Marengo, 2014: Climate change hotspots over South America: From CMIP3 to CMIP5 multi-model datasets. Theor. Appl. Climatol., 117, 579-587, doi:10.1007/ s00704-013-1030-x.

Turetsky, M. R., B. Benscoter, S. Page, G. Rein, G. R. van der Werf, and A. Watts, 2015: Global vulnerability of peatlands to fire and carbon loss. Nat. Geosci., 8, 11-14, doi:10.1038/ ngeo2325.

Wang, T., X. Lin, Y. W. Liu, S. Dantec-Nédélec, and C. Ottlé, 2016: Causes of uncertainty in China's net primary production over the 21st century projected by the CMIP5 Earth system models. Int. J. Climatol., 36, 2323-2334, doi:10.1002/joc.4497.

Wieder, W. R., G. B. Bonan, and S. D. Allison, 2013: Global soil carbon projections are improved by modelling microbial processes. Nat. Climate Change, 3, 909-912, doi:10.1038/ nclimate1951.

Williams, R. J., B. A. Myers, W. J. Muller, G. A. Duff, and D. Eamus, 1997: Leaf phenology of woody species in a North Australian tropical savanna. Ecology, 78, 2542-2558, doi:10.1890/0012-9658(1997)078[2542:LPOWSI]2.0.CO;2.

Wolf, S., and Coauthors, 2016: Warm spring reduced carbon cycle impact of the 2012 US summer drought. Proc. Natl. Acad. Sci. USA, 113, 5880-5885, doi:10.1073/pnas.1519620113.

Wood, T. E., M. A. Cavaleri, and S. C. Reed, 2012: Tropical forest carbon balance in a warmer world: A critical review spanning microbial- to ecosystem-scale processes. Biol. Rev. Cambridge Philos. Soc., 87, 912-927, doi:10.1111/j.1469-185X.2012.00232.x.

Wu, D., X. Zhao, S. Liang, T. Zhou, K. Huang, B. Tang, and W. Zhao, 2015: Time-lag effects of global vegetation responses to climate change. Global Change Biol., 21, 3520-3531, doi:10.1111/gcb.12945. 
Wu, X., H. Liu, X. Li, E. Liang, P. S. A. Beck, and Y. Huang, 2016: Seasonal divergence in the interannual responses of Northern Hemisphere vegetation activity to variations in diurnal climate. Sci. Rep., 6, 19000, doi:10.1038/srep19000.

Xia, J., Z. Yan, G. Jia, H. Zeng, P. Jones, W. Zhou, and A. Zhang, 2015: Projections of the advance in the start of the growing season during the 21st century based on CMIP5 simulations. Adv. Atmos. Sci., 32, 831-838, doi:10.1007/s00376-014-4125-0.

Yang, Y., J. Fang, W. Ma, and W. Wang, 2008: Relationship between variability in aboveground net primary production and precipitation in global grasslands. Geophys. Res. Lett., 35, L23710, doi:10.1029/2008GL035408.

Zappa, G., M. K. Hawcroft, L. Shaffrey, E. Black, and D. J. Brayshaw, 2015: Extratropical cyclones and the projected decline of winter Mediterranean precipitation in the CMIP5 models. Climate Dyn., 45, 1727-1738, doi:10.1007/s00382-014-2426-8.

Zhao, F., and N. Zeng, 2014: Continued increase in atmospheric $\mathrm{CO}_{2}$ seasonal amplitude in the 21 st century projected by the
CMIP5 Earth system models. Earth Syst. Dynam., 5, 423-439, doi:10.5194/esd-5-423-2014.

Zhao, J., H. Zhang, Z. Zhang, X. Guo, X. Li, and C. Chen, 2015: Spatial and temporal changes in vegetation phenology at middle and high latitudes of the Northern Hemisphere over the past three decades. Remote Sens., 7, 10973-10995, doi:10.3390/rs70810973.

Zhou, G., and Coauthors, 2013: A climate change-induced threat to the ecological resilience of a subtropical monsoon evergreen broad-leaved forest in southern China. Global Change Biol., 19, 1197-1210, doi:10.1111/gcb.12128.

Zhu, Z. C., and Coauthors, 2013: Global data sets of vegetation Leaf Area Index (LAI) $3 \mathrm{~g}$ and Fraction of Photosynthetically Active Radiation (FPAR)3g derived from Global Inventory Modeling and Mapping Studies (GIMMS) Normalized Difference Vegetation Index (NDVI3g) for the period 1981 to 2011. Remote Sens., 5, 927-948, doi:10.3390/ rs5020927. 